\title{
Design and Performance of the
}

10-kV, 5-MA Pulsed-Power

\section{System for the FRX-C}

\section{Compression Experiment}

D.J. Rej

G. A. Barnes

R. J. Gribble

J. E. Hinckley

T. W. Kreider

W. J. Waganaar

\section{DISCLAIMER}

This report was prepared as an account of work sponsored by an agsncy of the United States Government. Neither the United States Government nor any agency thereol, nur any of their employees, makes any warranty, express or impliad, or assumes any legal liability or responsibility for the accuracy, completeness, or usefuiness of any information, apparatus, product, or process disclosed, or represents that its use would not infringe privately owned rights. Reference herein to any specific commercial psoduct, process, or service by trade name, trademark, manufacturer, or otherwise does not necessarily constitute or imply its endorsemen, recommendation, or favoring by the United States Government or any agency thereor. The views and opinions of authors expressed herein do not necessarily stale or reflect those of the United States Government or any agency thereof.

\section{MASTER}




\title{
DESIGN AND PERFORMANCE OF THE 10-kV, 5-MA PULSED-POWER SYSTEM FOR THE FRX-C COMPRESSION EXPERIMENT
}

\author{
by \\ D. J. Rej, G. A. Barnes, R. J. Gribble, J. E. Hinckley, \\ T. W. Kreider, and W. J. Waganaar
}

\begin{abstract}
The design and performance of the pulsed-power system for the FRX-C compact toroid compression heating experiment are reviewed. Two inductively-isolated, 10-kV capacitor banks (total energy = $1.5 \mathrm{MJ}$ ) are discharged through a common, low-inductance load. The 5-MA currents are switched and crowbarred with parallel arrays of size-D ignitrons. Power supplies are constructed in simple 25 and $50 \mathrm{~kJ}$ modules, each capable of supplying $100 \mathrm{kA}$ at $10 \mathrm{kV}$. Non-negligible source inductance and the addition of highpower resistors maintain module isolation and protect the system during fault modes.
\end{abstract}

\section{INTRODUCTION}

The magnetic fusion facility $F R X-C / L S M^{1}$ at Los Alamos is being modified to enable highpower magnetic compression heating studies on field-reversed configuration (FRC) compact toroid plasmas. As illustrated in Figure 1, FRCs formed in a field-reversed theta-pinch will be translated into an adjacent coil where they will be compressed by a rapid increase in the cxternal magnetic field from 0.4 to $2.0 \mathrm{~T}$. After compression, the FRC will be translated and trapped in a third stage, formerly used on the $F R X-C / T$ device, ${ }^{2}$ where detailed confinement measurenients are planned. A principal scientific objective of the experiment is to study energy, particle, and magnetic flux transport of FRCs in a higher-pressure regime with a density and temperature product $n\left(T_{e}+T_{i}\right) \leq 10^{22} \mathrm{kev}-\mathrm{m}^{-3}$. The experiment will also serve as a proof-ofprinciple test of the translation-compression scenario envisioned in FRC fusion reaclor studies. $^{3}$ The major radius of the compressed plasma will be approximately $0.06 \mathrm{~m}$ while a thermal energy of up to $40 \mathrm{~kJ}$ is expected. This energy is of comparable magnitude to that obtained in a typical ohmic discharge on a large tokamak experiment such as the Princeton Large Torus. $^{4}$

In this report we review the design details and performance characteristics of the highvoltage, pulsed-power system for the $F R X-C$ compressor. Two large capacilor banks are discharged in parallel through the 3-m long, 0.46m-i.d., single-turn compression coil. First, the 0.5MJ guide-field bank is switched. This bank generates a pulsed oulput current of up to $1 \mathrm{MA}$ with risetime $110 \mu \mathrm{s}$. Immediately affer peak current, the guide-field bank is crowbarred. During the crowbar phase, the second capacitor bank is discharged. This is the 1-MJ compression bank, which delivers up to $4 \mathrm{MA}$ to the load with a risetime of $52 \mu \mathrm{s}$. The compression bank is also crowbarred at a time just after the maximum current. A high-power isolation inductor is placed in series with the guide-field bank to reduce the compression bank current in the guide-field crowbar loop.

The electrical circuil for the compressor is reviewed in Section II. The scientific and 


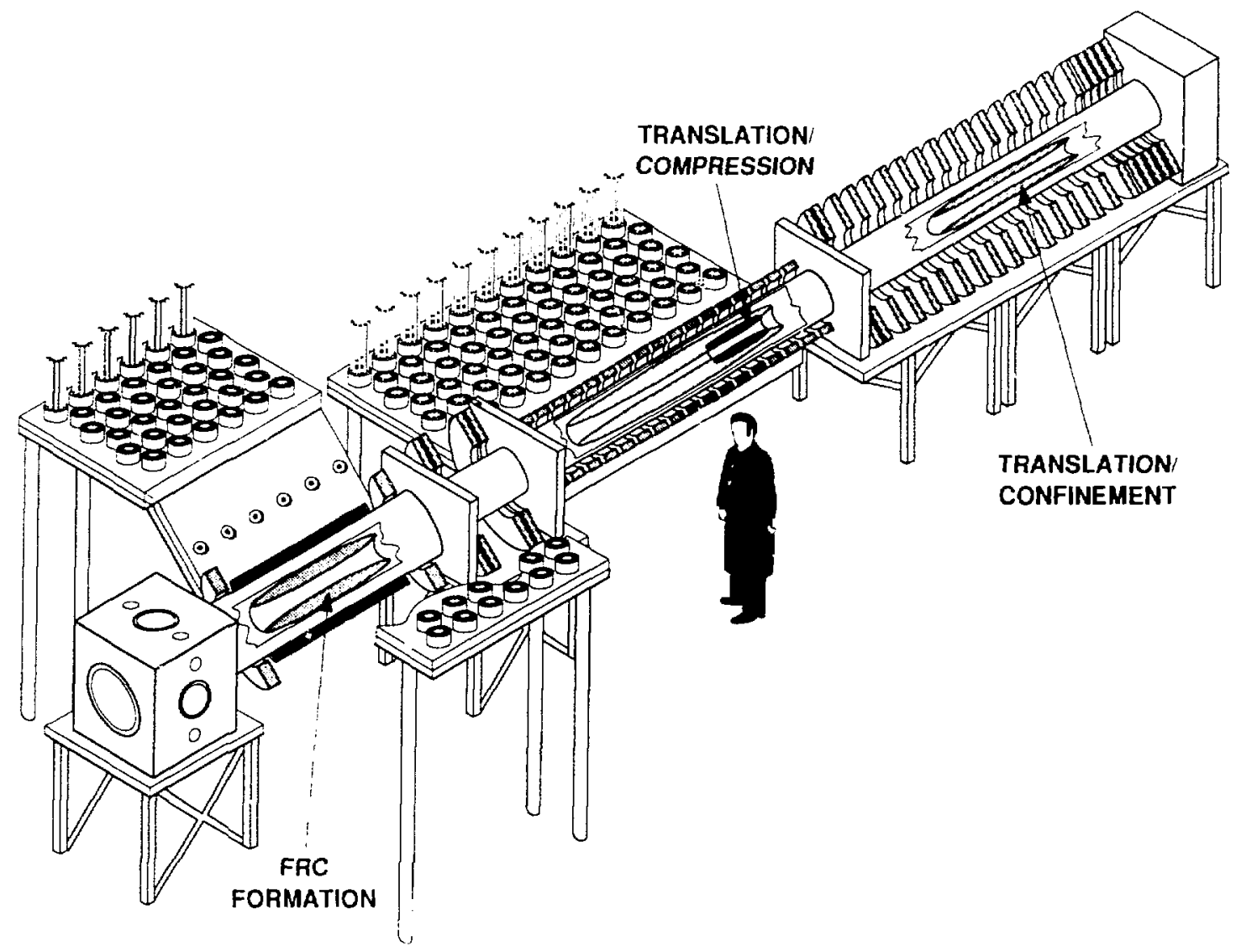

Fig. 1. Artist's conception of the FRX-C facility, modificd to cnable high-power compression heating of FRC plasmas.

technological requirements are discussed. The hardware design for the pulsed-power system is specified in Section III. The system is composed of fifty $10-\mathrm{kV}, 100-\mathrm{kA}$ modules, connected in parallel. The 5-MA current is transmitted through high-voltage cables and parallel plate transmission lines (collector plates) developed for the Scyllac program. The high-power isolation inductor is described in Section IV. Circuit analyses are performed in Section $V$ for both standard operation and fault modes. Non-negligible source impedances prevent excessive fault mode currents at the expense of reduced transfer efficiency to the load during normal operation. Extensive testing of prototype modules is reported in Section VI. Up to 2000 discharges at the full design rating have been obtained during these tests. Design details and prototype test results of the trigger system is considered in Section VII. The system cost of $\$ 0.20 /$ Joule is itemized in Appendix A.

\section{CIRCUIT REQUIREMENTS}

On $F R X-C / L S M$, a plasma thermal energy of approximately $10 \mathrm{~kJ}$ is confined over the time $T_{E} \simeq 100 \mu \mathrm{s}^{5}$ consequently, large auxiliary compression power to the plasma is required to offset the 100-MW losses and heat the FRC. It is desirable that the compression take place over a time scale shorter than $T_{E}$. It is also desirable to perform heating over a period that is greater than the longest equilibrium time-scale (the axial Alfven transit time), which for $F R X-C$ is about $10 \mu \mathrm{s}$. The external compression B-field has been designed within these scientific constraints, increasing from $0.4 \mathrm{~T}$ to $2.0 \mathrm{~T}$ sinusoidally with a quarter-cycle risetime $\tau_{y_{4}}=52 \mu \mathrm{s}$.

The compression magnet consists of a singleturn coil, 3.08-m long, 0.60-m o.d., 0.46-m nominal i.d., machined from type 6061/T6 aluminum plate. A 2-T vacuum B-field corresponds to $0.8 \mathrm{MJ}$ of 
magnetic energy in the coil. The vacuum flux swing of $0.27 \mathrm{~Wb}$ during the $52 \mu \mathrm{s}$ compression requires an initial loop voltage of $8.2 \mathrm{kV}$.

The magnetic energy and loop voltage can be comfortably supplied by an ignitron-switched capacitor bank connected to the coil through a single feed. The basic circuit for the $F R X-C$ compressor is shown in Figure 2. The $20-\mathrm{mF}, 10$ $\mathrm{kV}$, 4-MA compressor bank supplies the compression field. A crowbar is used to help sustain the peak coil current and to protect the capacitors against excessive voltage reversal. An additional $10-\mathrm{mF}, 10-\mathrm{kV}, 1-\mathrm{MA}$ caj acitor bank is required to provide the $i_{2}$ as $0.4-\mathrm{T}$ guide magnetic field into which the $F \mathrm{RC}$ plasma is translated. A 536-nH series inductance isolates the guide-field bank from the compression bank. The vacuum inductance of the compression coil is $63 \mathrm{nH}$. The source inductance and resistance values in Fig. 2 are those associated with the modular component design discussed in the next section.

The pulsed power is fed to the coil through low-inductance parallel-plate transmission lines or collector plates. In addition to the electrical constraints of high-voltage operation and low inductance, the collector plates must be designed to withstand large repulsive magnetic forces. For the $F R X-C$ compressor, the force associated with a 5-MA collector-plate current is 875 tons. Mechanically-strong, mylar-insulated collector plates developed for the Los Alamos Scyllac program satisfy these design constraints and have been recycled for use on $F R X-C$.

The capacitor banks are connected to the collector plates by several hundred parallel cables. Cable specifications and performance are reviewed in Sections III and VI, respectively.

The guide-field and compression capacitor banks are discharged sequentially. The guide-field bank is discharged early so that FRC formation and trauslation occur at the time of the peak guide-field current. The quarter-cycle risetime of the guide-field current is $110 \mu \mathrm{s}$. The guide-field bank is crowbarred shortly after the peak. The compression bank is discharged immediately after the FRC enters the compression coil while the crowbarred guide-field current is still near its peak value. The anticipated current and voltage waveforms illustrated in Figure 3 have been computed for $10-\mathrm{kV}$ bank voltages using the

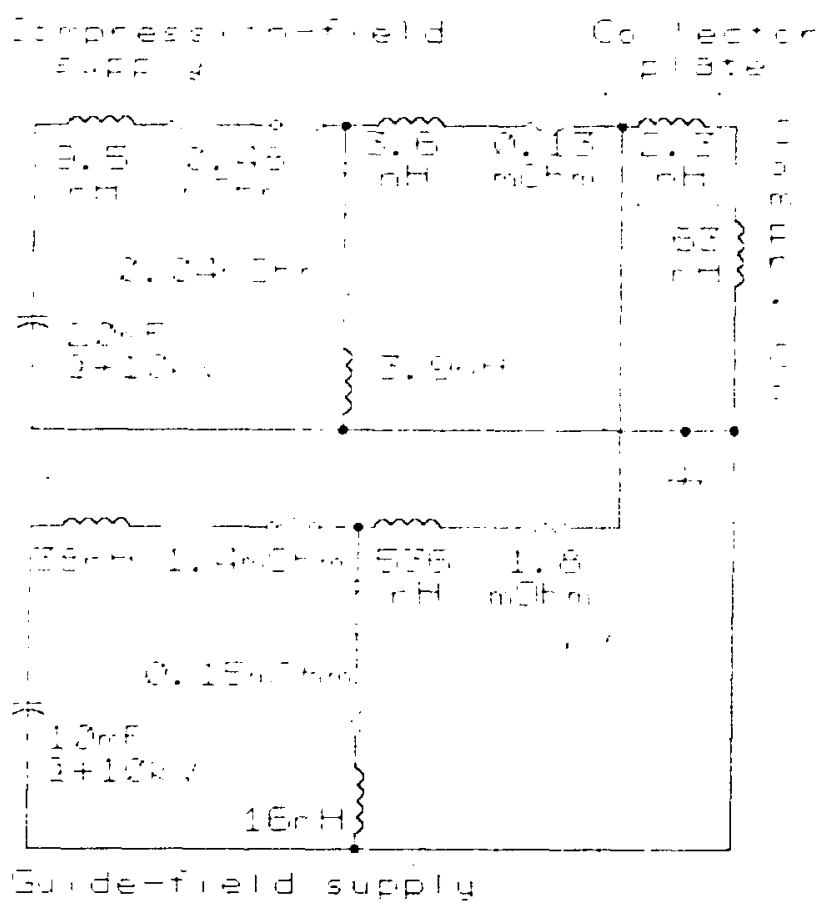

Fig. 2. Simplified circuit diagram of the FRX-C compression experiment.

circuit solver $S C A T T^{6}$ Added series resistances reduce the capacitor bank voltage reversals to acceptable levels (20\%). Just before the compression bank is fired $(\mathrm{t} \simeq 150 \mu \mathrm{s})$, most of the $0.5-\mathrm{MJ}$ guide-field bank energy is stored in the isolation inductor. When discharged, the compression bank current superimposes with the guide-field current. Currents add at the load and nearly cancel in the guide-field bank crowbar loop. Consequently, most of the energy stored in the isolation inductor is transferred to the load coil (see Figure 4). As with the guide-field, the compression bank is crowbarred just after the current maximum when the voltage reverses across the crowbar switch. The current decay time during the crowbar phase, $L / R \simeq 500 \mu \mathrm{s}$, is determined mainly from the coil inductance and the cable resistance.

The FRC plasma will influence the electrical circuit. When translated into the compression coil the FRC excludes guide-field flux. During translation, however, the guide-lield current in the coil remains approximately constant. Consequently, the FRC can expel up to one-half of the initial guide-field flux out of the coil. ${ }^{7}$ Another way to understand this effect is from a circuil 

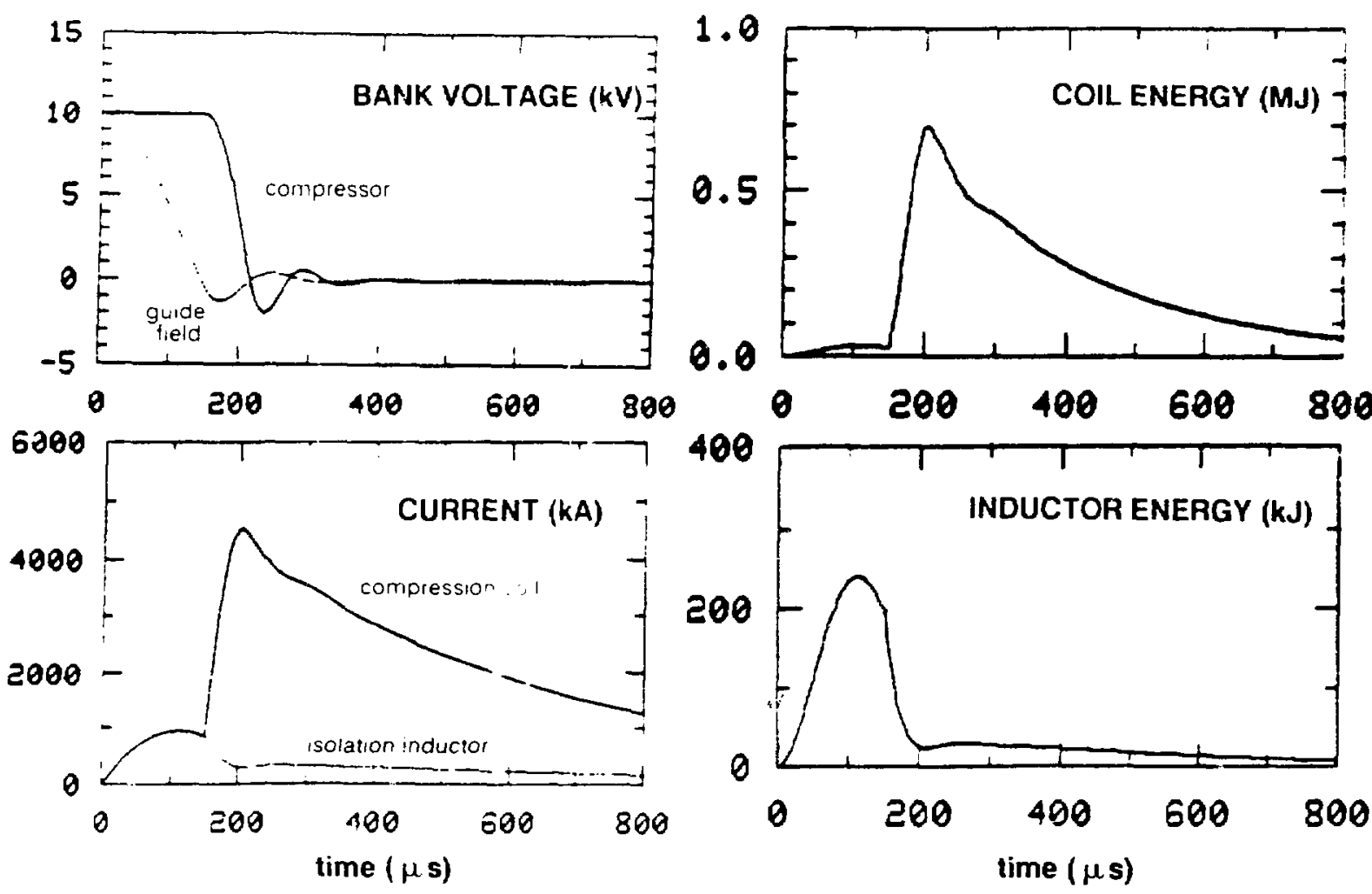

Fig. 3. Computed voltages and currents for a vacuum discharge with both guide-field and compression capacitor banks charged at $10-k$.

model. The arrival of the flux-excluding FRC will reduce the effective load inductance. The change in $\mathrm{L}$ results in an induced voltage of $\mathrm{I}(\mathrm{dL} / \mathrm{dt}) \leq$ $1.5 \mathrm{kV}$ across the coil. This voltage enhances the potential across the compression bank start switches.

The plasma can also influence the compression bank discharge parameters. The precompression plasma that arrives in the coil will reduce the initial load inductance by about $50 \%$. One, therefore, might expect larger peak coil currents $I_{\max }$ and faster risetimes $\tau_{4}$ with a plasma. However, there is also the important $\mathrm{I}(\mathrm{dL} / \mathrm{dt})$ term which is associated with the work done by the bank in heating the plasma and compressing the internal magnetic flux. The $\mathrm{I}(\mathrm{dL} / \mathrm{at})$ term acts like a damping term which tends to decrease $I_{\max }$ and increase $\tau_{4}$. The effects of the lower $\mathrm{L}$ and the $\mathrm{dL} / \mathrm{dt}$, therefore, tend to compensate one another.

Circuit computations have been performed to study plasma effects. The FRC is modeled as a flux-excluding cylinder with initial radius $r_{s}=$

Fig. 4. Magnetic energies stored in the compression coil and in the guide-field isolation inductance.

$0.16 \mathrm{~m}$ and length $\mathrm{z}_{\mathrm{s}}=2.2 \mathrm{~m}$. The magnetic field $B_{e}$ outside the FRC separatrix is computed given the coil current, the FRC dimensions, and using the constraint that flux is constant along the coil inner surface. The guide-field bank circuit is assumed crowbarred at $t=0$ with a current selfconsistent with a field $\mathrm{B}_{\mathrm{e}}=0.35 \mathrm{~T}$. Further details about the circuit model may be found in Appendix $B$. The evolution of the plasma dimensions during compression is computed from adiabatic theory ${ }^{8}$ applied to the low and high-flux FRC equilibria models. ${ }^{9}$ The circuit and plasma equations are then solved self-consistently. Results are shown in Figure 5. When comparing plasma and vacuum simulations, one finds that the magnetic fields vary up to $20 \%$, but that the compression-bank current and risetime remain essentially unchanged, because of the aforementioned compensating effects.

The simulations with plasma reveal the relative efficiencies of the $F R X-C$ compression experiment. Just over one-half of the total stored sapacitor bank energy is transferred to the load 

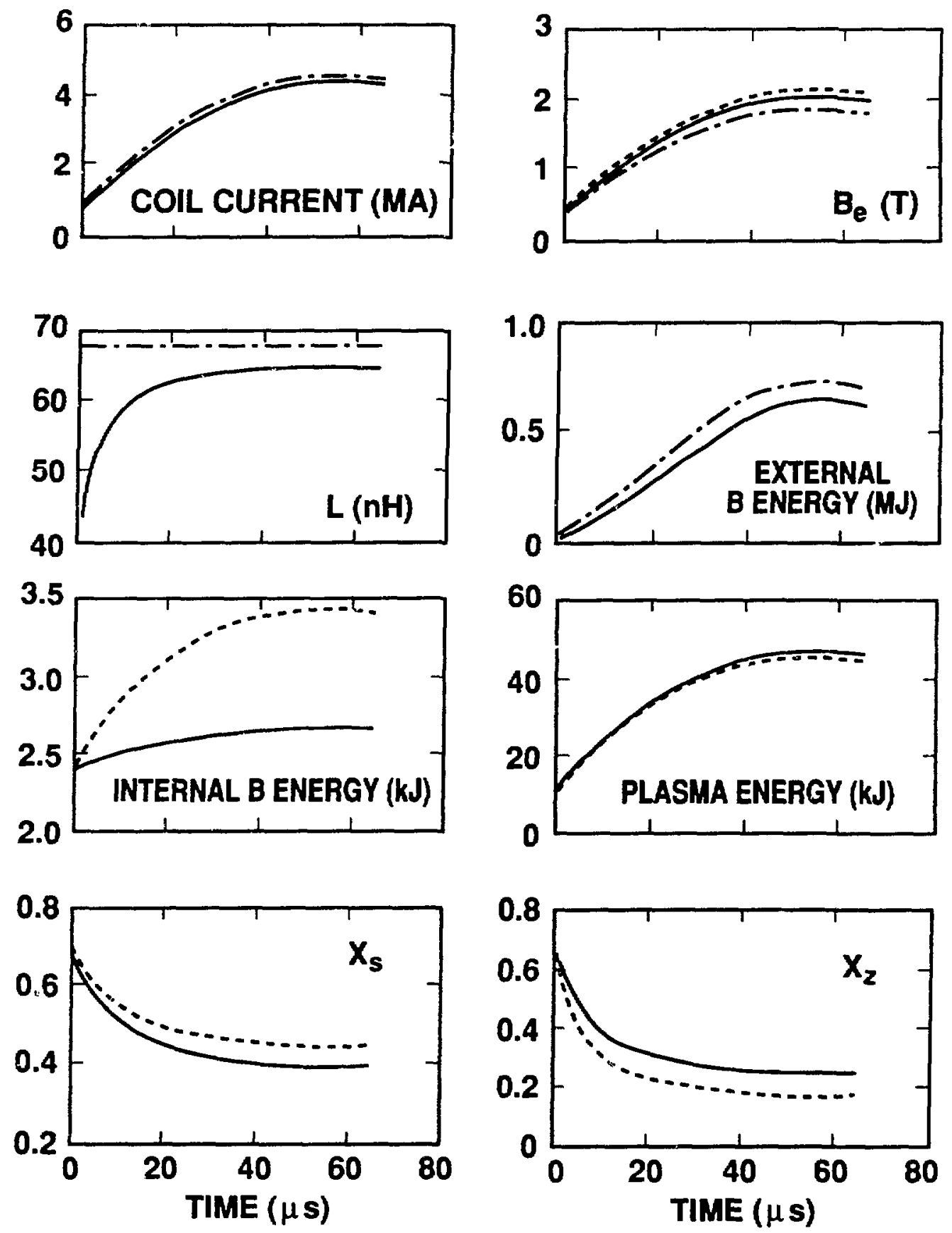

Fig. 5. Circuit simulations with high-flux (solid lines) and low-flux (dotted lines) FRC plasmas and initial conditions: $r=0.16 \mathrm{~m}$, $z_{s}=2.2 \mathrm{~m}$. Where applicable, vacuum calculations are aiso presented (dot-dashed lines). Consult Appendix B for further details.

coil. Approximately $35 \mathrm{~kJ}$ of that energy heats the plasma, while less than $1 \mathrm{~kJ}$ goes into the internal magnetic field. While an overall heating efficiency of $2.3 \%$ does not appear intuitively impressive, it does represent a cost-effective optimum. It is difficult for other technologies (e.g., 500-MW, 50- $\mu s \mathrm{rf}$ or neutral beam injection) to attractively compete with magnetic compression. Plasma translation coupled with compression increases the efficiency. Since most of the capacitor bank energy ultimately goes into providing the external magnetic field outside the plasma, one wants the 
initial pre-compression plasma to occupy as much of the coil volume as possible. FRC translation into a smaller-diameter coil helps establish this initial condition. If comparable compression heating experiments were to be performed in situ in the $F R X-C / L S M$ source, more energy would be needed in the larger-volume $\theta$-pinch coil. Furthermore, there exists the additional problem with in situ experiments in that one must isolate the low-impedance, $60-\mathrm{kV} \theta$-pinch capacitor bank from the compression bank. The large impedance associated with this isolation dramatically reduces $\theta$-pinch transfer efficiencies during field-reversal and FRC formation.

The compression coil diameter and length are optimized. An annular vacuum region is needed to insulate the hot FRC plasma from the cold quartz vacuum chamber wall. In experiments to date, it has been desirable to keep the FRC separatrix radius less than $75 \%$ of the vacuum wall radius. The $0.41-\mathrm{m}-\mathrm{i}$.d. vacuum chamber and 0.46 m-i.d. compression coil are designed to meet this physics constraint. These dimensions also represent a technological optimum. In general, less magnetic energy is required in a smallerdiameter coil; however, a decreased diameter results in a diminished return. The translated plasma fills a larger portion of coil area, but the coil must be lengthened to accept the longer plasma that results from increased wall compression and flux decompression. From adiabatic theory ${ }^{8}$ one finds that in the limit of an isothermal translation, the compression coil volume scales as $r_{w}{ }^{a} / \beta^{b}$, where $r_{w}$ is the coil radius, $\beta=1-\frac{w}{2}\left(r_{s} / r_{w}\right)^{2}$, and the profiledependent coefficients $1 \leq a \leq 4 / 3$ and $1 / 3 \leq b$ $\leq 1$. The required capacitor bank energy does not decrease linearly with coil volume because a decreased diameter and increased length cause the coil inductance to drop. Source impedances become increasingly important and the transfer efficiency decreases. As an example, we consider a 0.32-m-i.d. compression coil. For this situation the coil parameters would be as follows: length $\simeq$ $4.7 \mathrm{~m}$, inductance $=21 \mathrm{nH}$, magnetic energy (for $2-\mathrm{T}$ vacuum field) $=0.60 \mathrm{MJ}$. The required compression capacitor bank energy would be approximately $1.0 \mathrm{MJ}$, the same value needed for the $0.46-\mathrm{m}$-i.d. coil.

There are alternate heating methods that could result in better coupling to the plasma. For example, the translation feature could be further exploited in a staged compressor. Staging is a variation on the compression-heating theme through which the external magnetic field energy is minimized. The FRC would be translated and partially compressed in successively smaller coils, thereby reducing the volume outside the FRC which contains the largest magnetic field. This concept was appreciated during the early days of fusion research by a Livermore group who compressed mirror plasmas in a three-stage experiment. ${ }^{10}$ The staged compressor, while clever in principle, is not necessarily straightforward to implement in practice. Each stage requires a separate coil, guide-field and compressor pulsedpower supplies, and transmission line circuitry. A related concept is the "travelling mirror compressor"11 in which a mirror pulse propagates along a conical coil. A pulse-forming network is employed to strengthen and steepen the mirror as it propagates. It is unclear whether or not this scheme easily extrapolates to the $1-\mathrm{GW}$ heating levels required on $F R X-C$.

Another alternate, and possibly more efficient, heating technique is magnetoacoustic heating. Oscillation of the external field over a time-scale comparable or shorter than an Alfven transit time usually results in efficient plasma heating. $^{12}$ For $F R X-C / L S M$, the oscillation frequency can be as low as $20 \mathrm{kHz}$. Magnetoacoustic heating becomes an intriguing option, especially since the $F R X-C$ compressor can be easily modified to allow exploratory studies. The modification would consist of a $97.5 \%$ reduction in compression bank capacitance and the removal of the crowbar trigger. The guidefield system would remain unchanged. As illustrated in Figure 6, the vacuum current (or Bfield) would be modulated up to $50 \%$ at $22 \mathrm{kHz}$, with a damping factor $Q=22$.

The overall heating efficiency also could be increased with wall (i.e., imploding-liner) compression rather than flux compression. Liner compression of FRCs has been studied on the TOR-LINER facility at the Kurchatov Institute in the Soviet Union. ${ }^{13}$ Successful heating was inferred from a large neutron flux. While more efficient, liner compression is messy since a sizable fraction of the experiment is destroyed during a discharge and the repetition rate is low. The flux compression is desirable on FRX-C in 


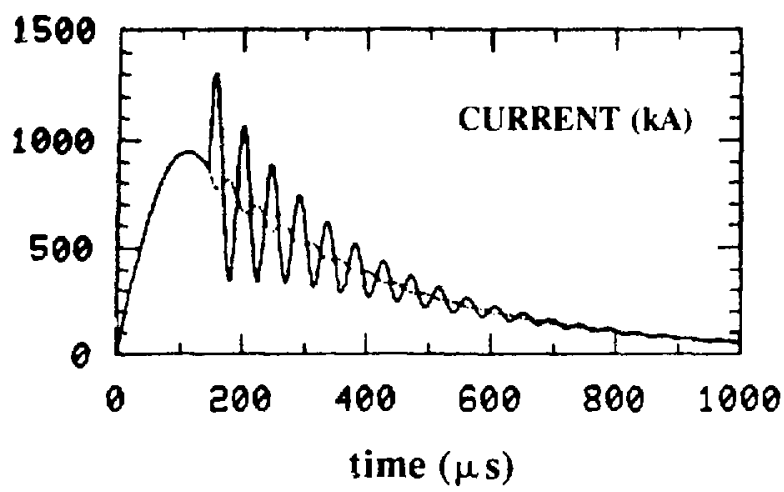

Fig. 6. Vacuum circuit simulations of a possible magnetoacoustic heating experiment on FRX-C. Currents in the compression coil (solid line) and isolation induclor (dotted line) are plotted against time.

view of the higher repetition rate (typically 6 shots per hour) and its compatibility with routine plasma diagnostics used in magnetic fusion research.

\section{MODULE DESIGN}

The 10-kV compressor and guide-field pulsed-power supplies are constructed from modules. Each module consists of one or two capacitors, a pair of ignitrons for start and crowbar switching, cables, and busbars.

The "size- $\mathrm{D}$ " ignitrons have been chosen over the larger "size-E" model for three reasons. First, there exists a more extensive performance data base for the D-tube. In particular, the following conservative operational parameters have been established after approximately one thousand 58MJ discharges through 234 tubes on the NOVA laser at Livermore: ${ }^{14}$ hold-off voltage $=11 \mathrm{kV}$, peak current $=140 \mathrm{kA}$, and charge transfer $=$ $70 \mathrm{C}$. [Note: These values are significantly lower than those specified by the manufacturer: $25 \mathrm{kV}$, $300 \mathrm{kA}, 200 \mathrm{C}$.] Second, preliminary laboratory tests at Livermore indicate that the moreexpensive E-tubes do not perform any better than the size-D. ${ }^{15}$ The third reason for the selection of the D-tube is the tube inductance. The source impedance is kept low by using a larger number of the lower-inductance D-tubes.

The principal parameter that influenced the design of the FRX-C modules is the output current. In particular we have designed a system in which ignitron currents are kept at or below the NOVA operational value of $140 \mathrm{kA}$. Because of ringing through the start ignitron loop, the peak current in a crowbar tube can be $40 \%$ larger than the output current. Therefore, each module has been designed to supply and crowbar $100-\mathrm{kA}$ output at a 10-kV charge. Accordingly, the FRX-C compressor and guide-field banks consist of $\mathbf{4 0}$ and 10 modules, respectively.

Type NL488A ignitrons have been selected for the $F R X-C$ modules. The basic tube was designed by the General Electric Company and is currently available either as the $N L 488 A$ from National Electronics, Geneva Illinois, or as the $B K 488 A$ from English Electric Valve Ltd., Lincoln UK. The 488A was chosen because of its busbar anode construction. Braided "pigtail" anodes found on other size-D tubes (e.g., the $N L-2888 A$, $N L-37207 A$, or the $N L-5553 B$ ) have occasionally failed during previous high-current applications. As discussed in Section VI, a temperature differential between the anode and cathode is absolutely necessary to prevent tube prefire. The cathode jacket is maintained between $10^{\circ}$ and $15^{\circ} \mathrm{C}$ by a circulating deionized water system. The relatively low mercury vapor pressure $(0.6 \mathrm{mtorr})$ has not caused significant jitter in our prototype tests. There is no active anode temperature control; however, as explained below, the start tube anodes are passively heated by a series resistor connected to the anode bus.

Given load and source impedance characteristics, and the desired bank risetimes, one determines the required capacitance: $0.5 \mathrm{mF}$ for a compressor module (25-kJ stored energy at $10-\mathrm{kV}$ charge) and $1.0 \mathrm{mF}$ for a guide-field module $(50 \mathrm{~kJ}$ at $10 \mathrm{kV})$. Industry can readily provide a single $10-\mathrm{kV}, 25-\mathrm{kJ}$ capacitor, capable of 10,000 discharges at $100 \mathrm{kA}$ and $20 \%$ reversal. 50kJ units are also available, albeit at substantially reduced discharge and reversal ratings. Because of these ratings, $25-\mathrm{kJ}, 10-\mathrm{kV}$ capacitors (General Electric Co., Catalogue \# 30F1695) have been chosen for both the 25 and 50-kJ modules. With connecting hardware, the equivalent series resistance (ESR) and inductance (ESL) of a capacitor are $11 \mathrm{~m} \Omega$ and $0.10 \mu \mathrm{H}$, respectively.

The engineering design of the $25-\mathrm{kJ}$ module for the $F R X-C$ compressor is detailed in Los Alamos National Laboratory (LANL) Drawings 45Y-232196 (9 sheets). The assembly drawing (sheet J1) is included in Appendix C of this report. The start and crowbar ignitrons and the $25-\mathrm{kJ}$ 
capacitor form the nucleus of a module. The remaining components have been designed with a number of objectives: (1) efficient and reliable energy transfer with adequate inductive isolation and fault-current protection; (2) low-cost; (3) light weight; and (4) simple assembly, inspection, and maintenance. Some objectives are mutually exclusive. For example, relatively large component inductance allows easy access, adds high-voltage insulation, and provides component isolation at the expense of reduced energy transfer efficiency. The $0.4 \mu \mathrm{H}$ total inductance of a module represents an optimization between efficiency and isolation.

A photograph of a prototype $25-\mathrm{kJ}$ module is shown in Figure 7. Power flow is along a parallelplate "strip-lines" made from 6061/T6 aluminum busbars. The busbars are held together by clamps and spacers made from NEMA-Grade G-10 laminate, connected by stainless steel bolts (Figure 8). The busbars are spaced $32 \mathrm{~mm}$ apart and are insulated only by ambient air and the G10 strips. Each ignitron is mounted and housed inside a welded-aluminum cage (Figure 9). The
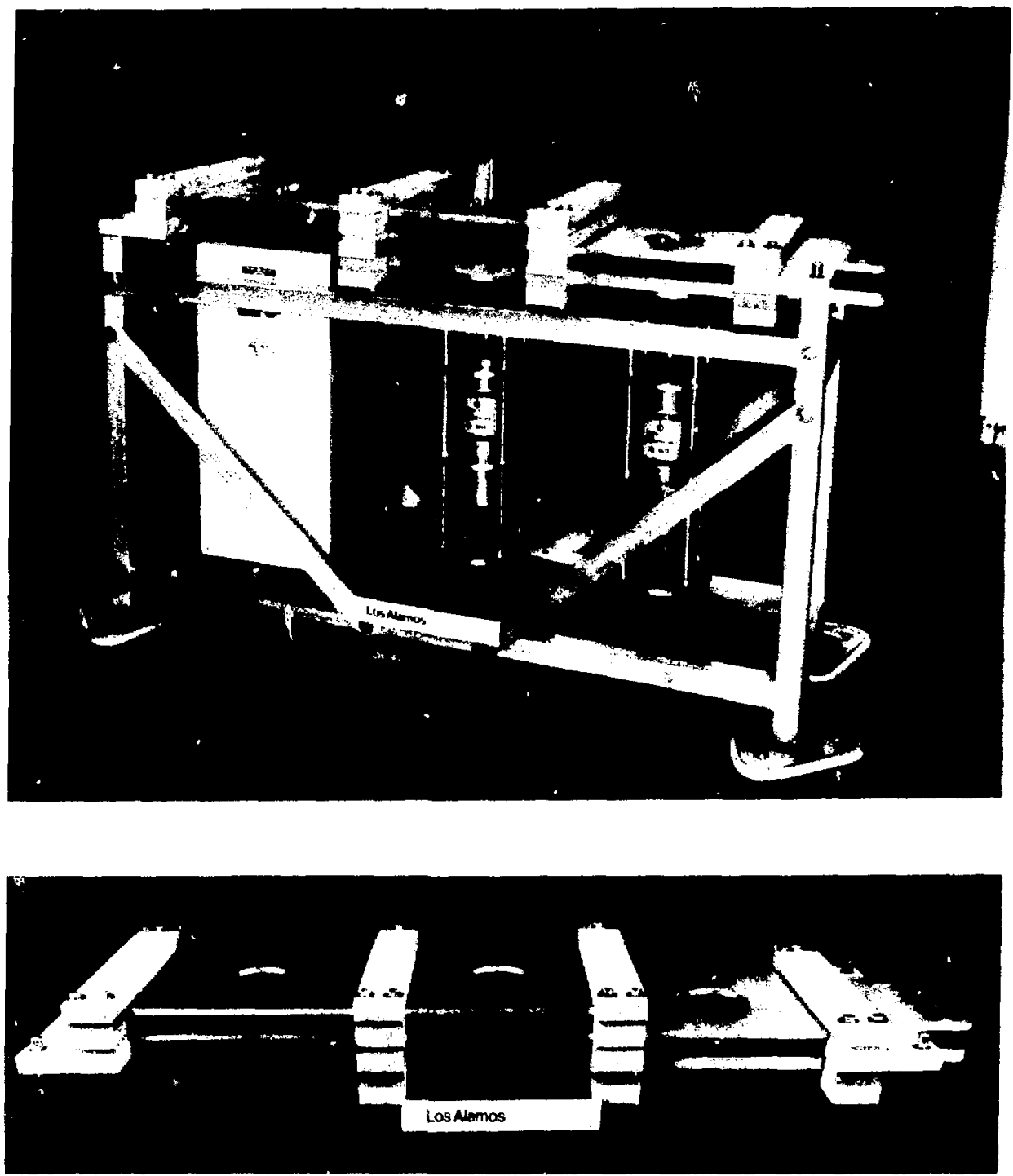

lig. 8. Busbar assenibly for the $25-\mathrm{kJ}$ module. 


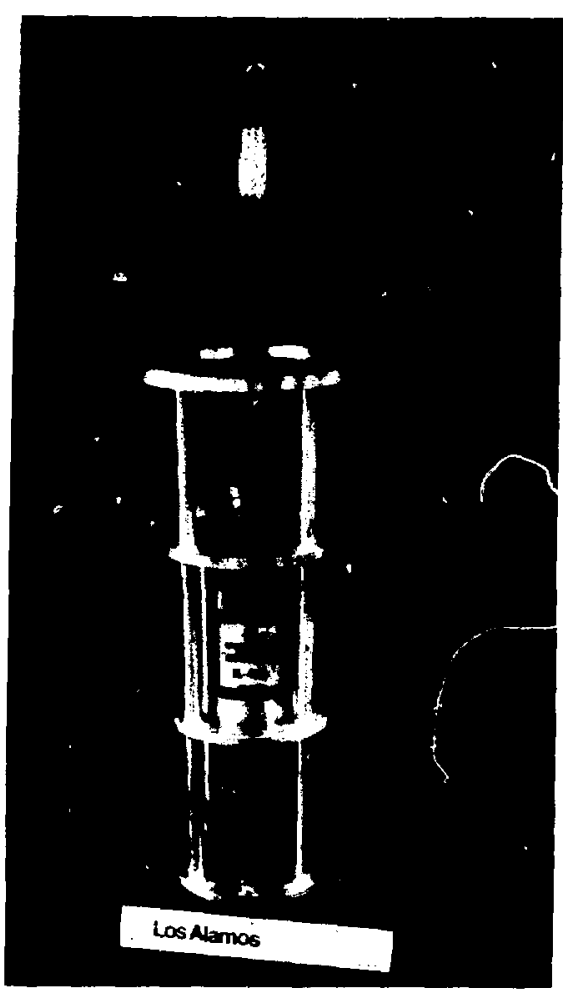

Fig. 9. Ignitron assembly shown with inconel damping resistor. cathode bar is affixed rigidly to the cage bottom with annealed copper brackets. The cage top connects to the lower busbar through copper gaskets. The fragile glass-metal seal around the anode bar is isolated from mechanical shock through a pair of high-current flexible braided connectors (Model \# CF 771-7.25-D6667 and \# CF 771-11-D6667, available from the Dossert Corp., Waterbury Connecticut). Brass hex stock is used to extend the capacitor high-voltage termina! 97-mm above the low-profile header. The hex stock and the low-voltage capacitor connections are connected to the busbars with copper sheet metal. The busbar-ignitron assembly and the capacitor are held in position by a space frame made from square aluminum tubing (Figure 10). The busbar assembly and frame are designed so that modules may be stacked on top of one another as illustrated in Figure 11.

An important module component is a $7-\mathrm{m} \Omega$ damping resistor that is installed in series with every start ignitron. The purpose of the resistors is to protect equipment during standard operating and fault modes. During a standard discharge, the resistors reduce the capacitor voltage reversal; furthermore, they help damp the ringing start ignitron current during the crowbar phase. The

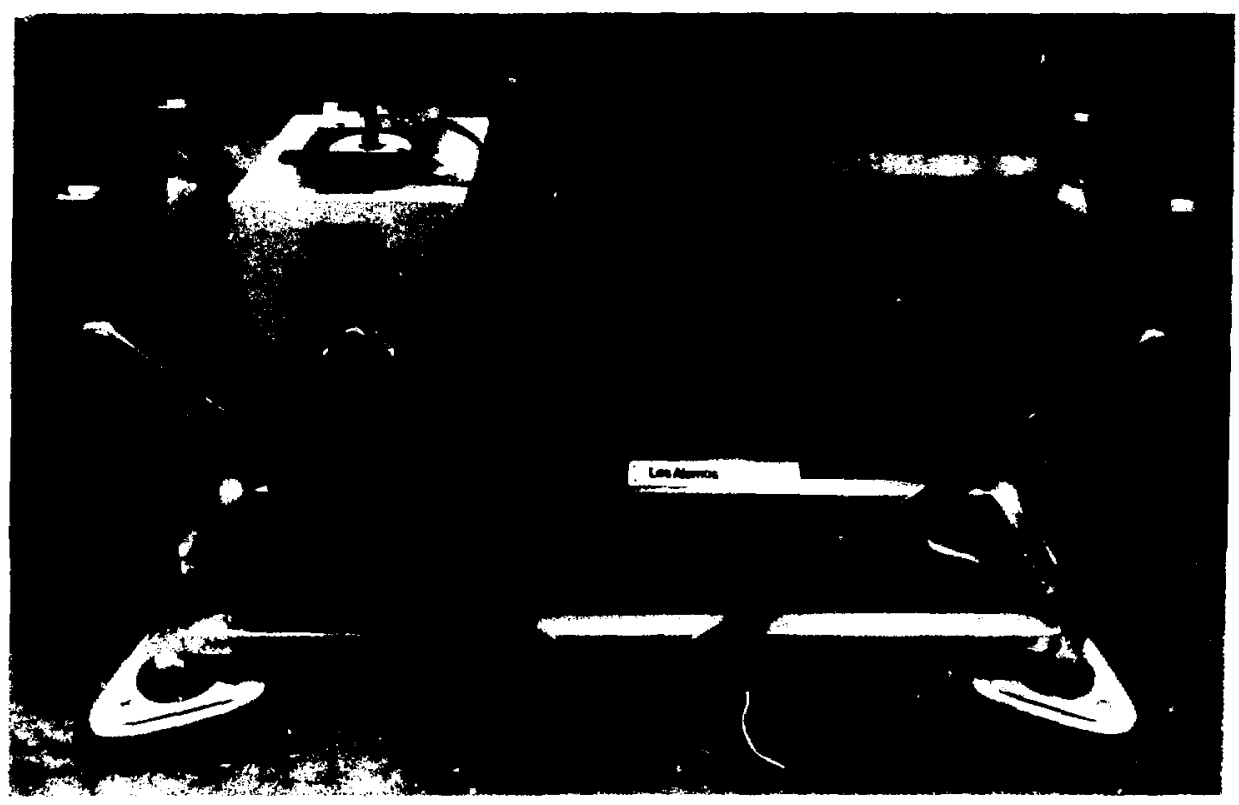

Fig. 10. Wide-angle photograph of a prototype $25-\mathrm{kJ}$ module frame and capacitor assembly. 


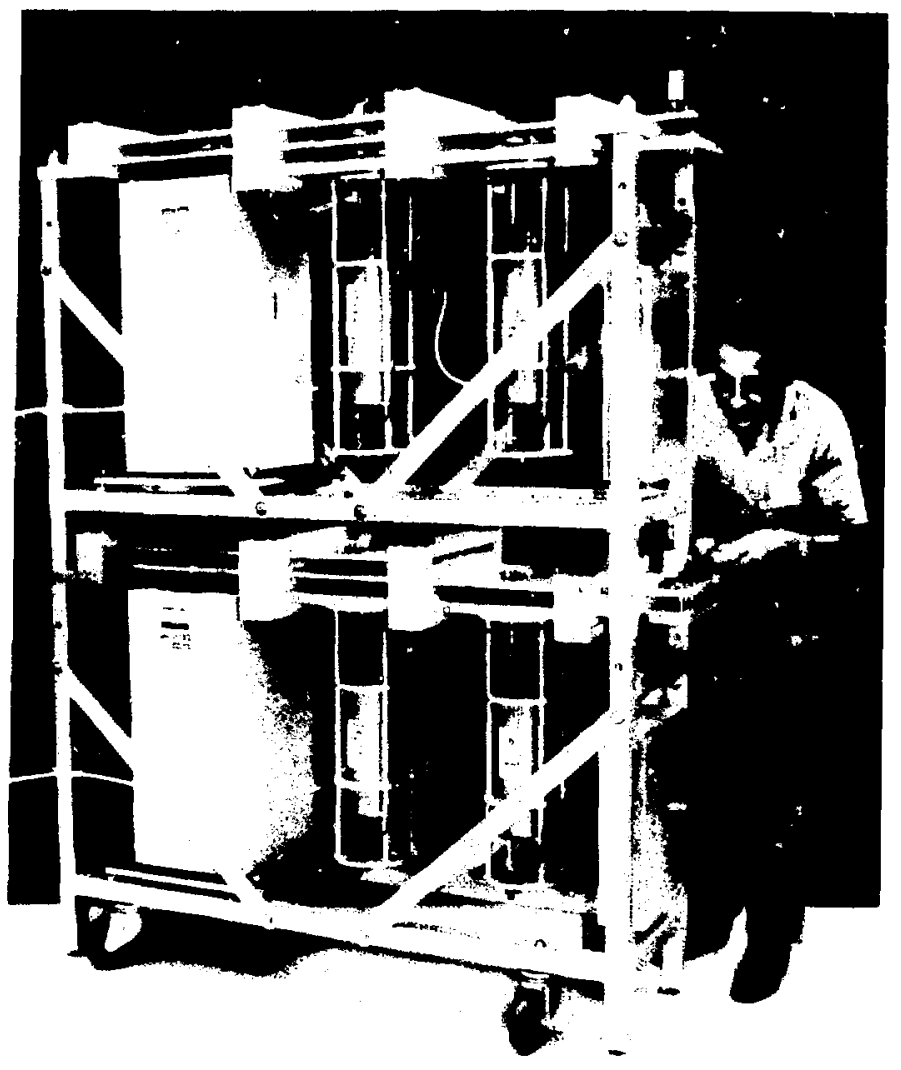

Fig. 11. Photograph of two stacked 25-kJ modules for the FRX-C compression bank-

resistors limit the current during fault modes such as a start or crowbar ignitron pre-fire. A crowbar "no-fire" constitutes another potentially dangerous fault. In this mode, the resistors help damp ringing voltages and currents. These effects are discussed in more detail in Sections $V$ and VI.

A resistor consists of two parallel strips (230$\mathrm{mm}$ long $\times 25-\mathrm{mm}$ wide) of 0.8 -mm-thick, type625 inconel sheet metal. Metal tabs (50-mm long $\times 25-\mathrm{mm}$ wide) are bonded to the ends of each strip to insure good electrical connection for the 50-kA current. Two different tab materials have been tested, type-200 nickel and OFHC copper. The nickel is bonded to the inconel through a vacuum e-beam weld, the copper through a vacuum furnace braze. The resistor assemblies are connected with bolts directly to start ignitron anode and to the flexible braided connector ( $c f$. Figure 9).

The 100-kA output current is transmitted from a module by twelve parallel coaxial cables.
The low-inductance cable, Belden type YK-198, has been selected for the $25-\mathrm{kJ}$ module. The manufacturer's specifications ${ }^{16}$ for the cable are as follows: outer diameter $=14.4 \mathrm{~mm}$, breakdown voltage $=50 \mathrm{kV}$, inductance $=27 \mathrm{nH} / \mathrm{ft}$, capacitance $=103 \mathrm{pF} / \mathrm{ft}$, inner conductor resistance $=$ $1.038 \mathrm{~m} \Omega / \mathrm{ft}$, outer conductor resistance $=$ $1.031 \mathrm{~m} \Omega / \mathrm{ft}$. Cables are connected to busbars at one end of the module. The outer braids are connected by hoseclamps to copper couplings swaged into the middle bus. The inner conductors are crimped onto brass "banana-plug" connectors which are slotted and plugged into the lower bus. The opposite ends of the cables are connected to the collector plates with similar connections made through Scyllac cable cartridges.

The equivalent electrical circuit for a $25-\mathrm{kJ}$ module is given in Figure 12. The capacitor, busbar, and ignitrons contribute about equally to the $0.4-\mu \mathrm{H}$ module inductance. The ignitron-cage assembly inductance is about four-times larger 


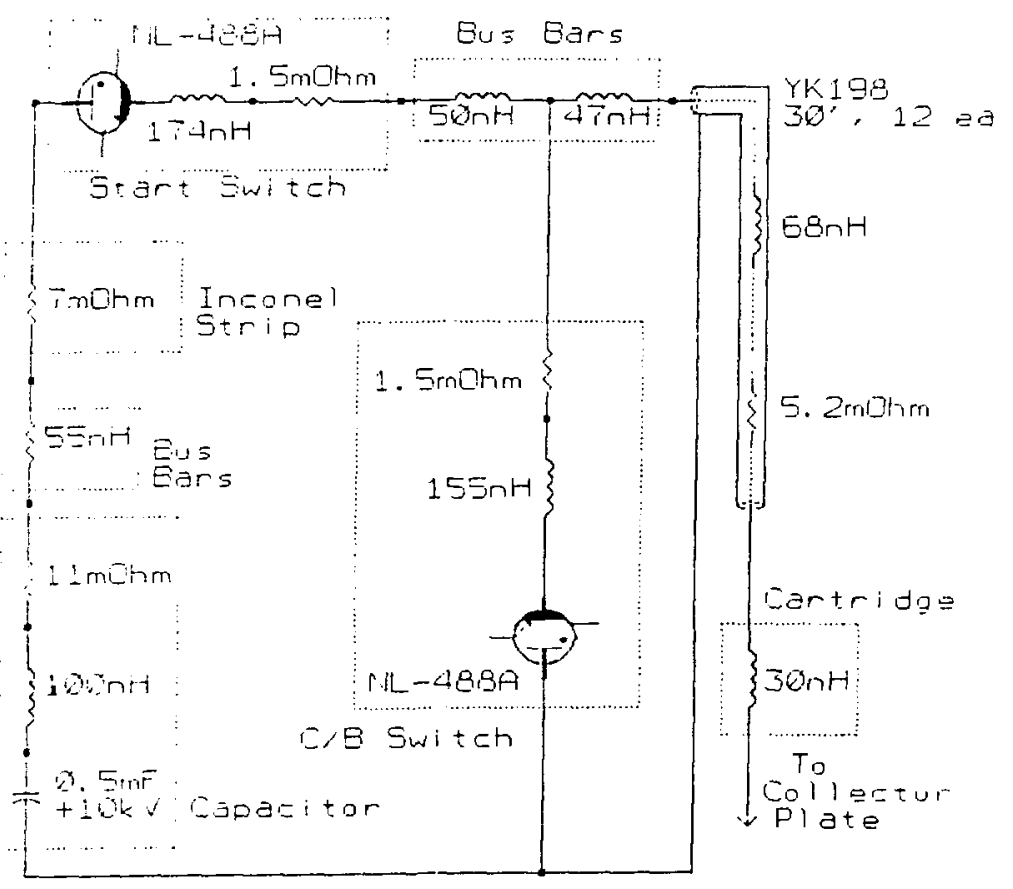

Fig. 12. Simplified circuit diagram for a single $25-\mathrm{kJ}$ module.

than the $40-\mathrm{nH}$ value for the bare ignitron. Most of this increase results from the extended cathode and anode connections. The relatively large inductance of the busbar is a result of the $32-\mathrm{mm}$ gap, and the relatively long module length of $1.6 \mathrm{~m}$. For low-impedance loads, the ignitron cage and busbar dimensions could be decreased, at the expense of increased insulation and assembly problems.

The 50-kJ guide-field module is a "stretch" version of the $25-\mathrm{kJ}$ module. Two $0.5-\mathrm{mF}$ capacitors are used. The frame and busbars are elongated to accommodate the extra capacitor. The other components from the $25 \cdot \mathrm{kJ}$ module are compatible with this design. The engineering design of the $50-\mathrm{kJ}$ module is detailed in LANL drawing \# 45Y-232200 (4 sheets). The higherinductance $R G-217 / U$ cable has been selected for the guide field bank to better isolate modules from one another. The cable specifications are as follows: $\quad$ o.d. $=13.8 \mathrm{~mm}$, voltage standoff $=$ $12 \mathrm{kV}$, inductance $=95 \mathrm{nH} / \mathrm{ft}$, capacitance $=30$ $\mathrm{pF} / \mathrm{ft}$, inner conductor resistance $=0.9 \mathrm{~m} \Omega / \mathrm{ft}$, outer conductor resistance $=1.1 \mathrm{~m} \Omega / \mathrm{ft}$. Cable connections are similar to those used with the $Y K$ 198 , except for the brass banana plug which is soldered to the $R G 217 / U$ center conductor.

\section{IV, ISOLATION INDUCTOR}

A 536-nH inductance is placed in series with the guide-field bank (see Fig. 2). The purpose of this isolation inductance is to reduce the amount of current from the compression bank that flows through the guide-field crowbar ignitrons. Most of this isolation is provided by a $462-\mathrm{nH}$ inductor that is placed in series between the ten $50-\mathrm{kJ}$ modules and the collector plate cartridges. Approximately one-half of the 0.5-MJ energy in the guide-field capacitor bank energy can be stored in the inductor during the 1-ms, 1-MA pulse.

The isolation inductor is a coaxial conductor shorted at one end. On the open end, the $R G 217 / U$ cables from the $50-\mathrm{kJ}$ modules connect to the center and the YK-198 cable from the cartridges connect to the outer conductor. Cable connections are identical to those used on the capacitor bank modules. The inductor is made from type-6061/T6 aluminum with dimensions: length $=1.00 \mathrm{~m}$, outer conductor i.d. $=0.91 \mathrm{~m}$, center conductor $0 . d$. $=0.10 \mathrm{~m}$. Relatively thick material and welds are used in the construction so that the inductor will withstand the large pulsed magnetic forces (up to 215 tons). Further 
engineering details for the isolation inductor can be found in LANL drawing 45Y-232203 (5 sheets), from which the assembly drawing is included as Appendix D in this report.

\section{CIRCUIT SIMULATIONS}

The circuit equation solver has been used to simulate the anticipated module performance. The calculated ignitron current and charge transfer plotted in Figure 13 are for the same simulation shown in Figure 3. The charge transfer is always less than the 70-C design limit. The capacitor ESR and the inconel series resistors keep the start ignitron current reversals to under $40 \%$. This ringing causes the peak crowbar ignitron current to be $40 \%$ larger than the output current. Without the inconel resistor, the peak current reversal is $63 \%$. Finite inductance is responsible for the $45 \mu \mathrm{s}$ crowbar current risetime. In these simulations the ignitron resistance $R_{i}$ is assumed constant at $1.5 \mathrm{~m} \Omega .^{17}$ [Note: This assumption is incorrect just after triggering when the ignitron current is less than $20 \mathrm{kA}$. The empirical relation ${ }^{17} R_{i} \simeq 9.31^{-0.55}$

I (kA)

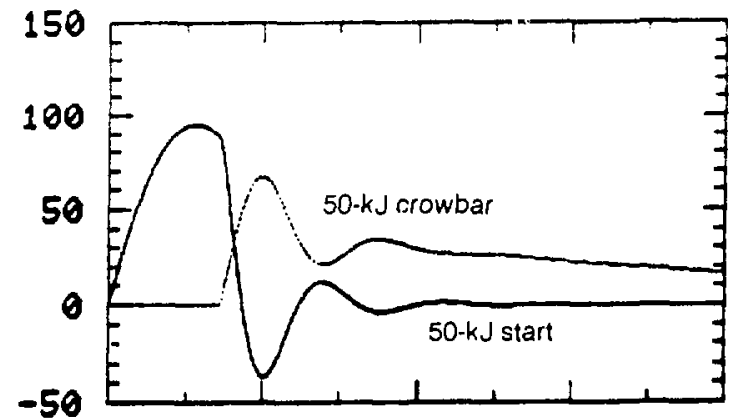

(] (C)

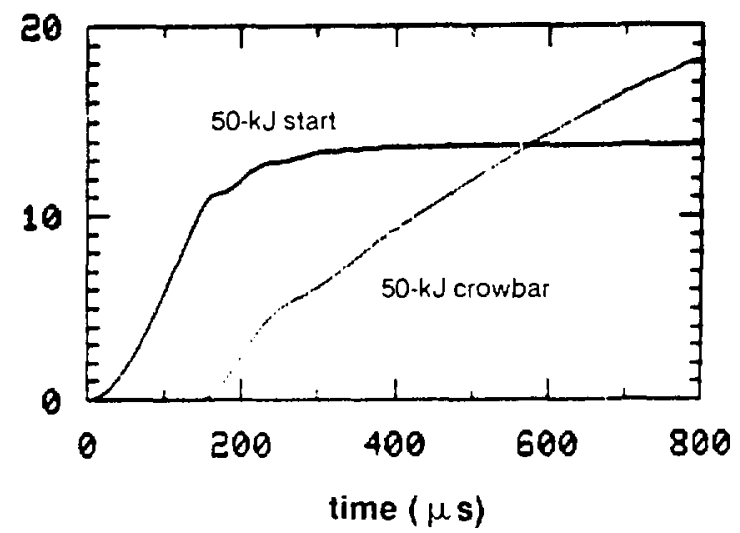

(where $R$ is in milliohms and $I$ is $k A$ ) would have been a more accurate choice in the low current limit, I $<20 \mathrm{kA}$; however, the effect is small, in view of other impedances, larger than $R_{i}$, in the circuit.]

During a normal discharge, up to $15 \%$ of the capacitor energy is dissipated in the inconcl resistor (see Figure 14). A $10-\mathrm{kV}$ discharge will cause the inconel temperature to rise by $110^{\circ} \mathrm{C}$ (25-kJ module) or $190^{\circ} \mathrm{C}$ (50-kJ module). Inconel 625 was chosen to be the resistor material because of its large electrical resistivity $(1.29 \mu \Omega-\mathrm{m}$ at room temperature). Fortunately, this alloy also has a small thermal expansion coefficient; consequently, the resistors expand by only $0.17 \%$ (i.e., by $0.4 \mathrm{~mm}$ ) when heated $200^{\circ} \mathrm{C}$ above room temperature. The inconel is effectively cooled by convection of ambient room air during the ten minutes between shots. A small fraction of this heat is also conducted to the ignitron through the anode-resistor current joint. This heat, combined with the cathode cooling, "conditions" the tube. The temperature differential prevents mercury condensation near the anode, thereby maintaining the ignitron high-voltage standoff capability.
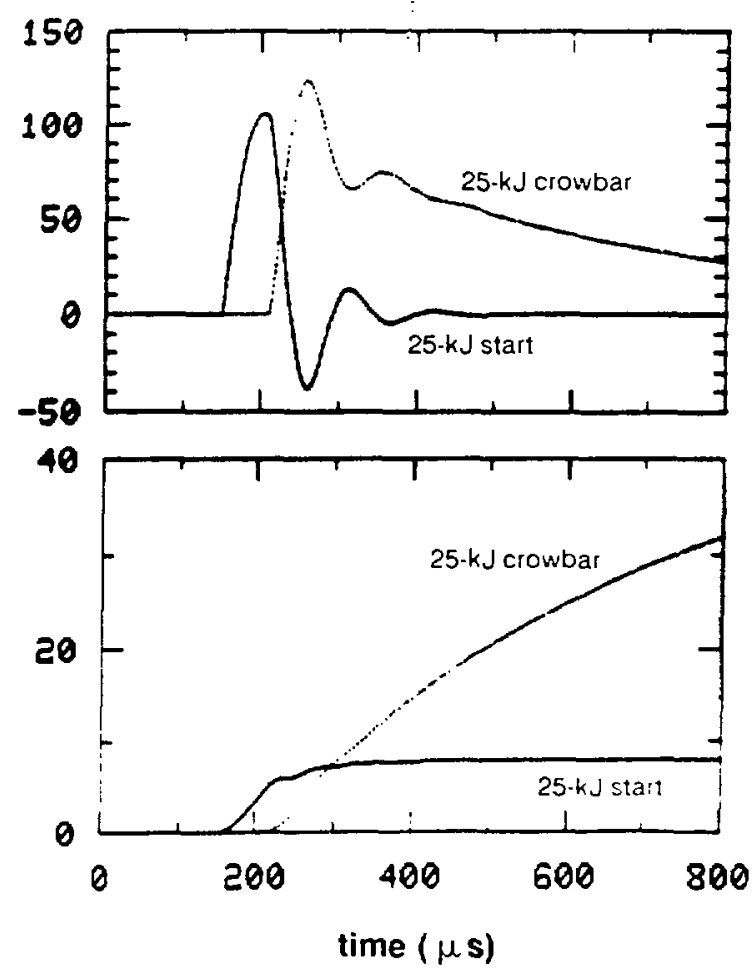

Fig. 13. Calculated ignitron currents and charge Iransfers for' a $10-\mathrm{k} V$ discharge. 


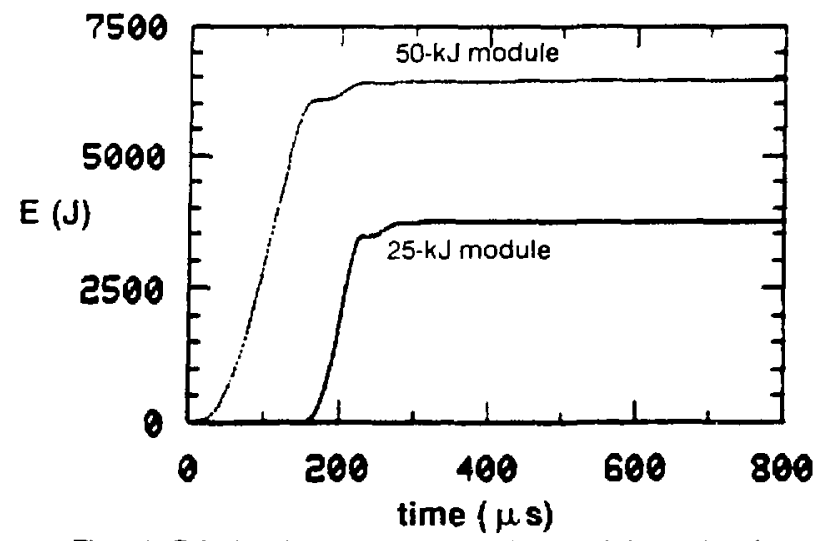

Fig. 14. Calculated energy deposited into each inconel series resistor for a $10-\mathrm{kV}$ discharge.

At the expense of decreased transfer efficiency, the finite source inductance inhibits ignitron deterioration in at least two ways. First, a larger inductance distributes the crowbar current uniformly through the forty parallel tubes. The source impedance should be greater than the nominal ignitron resistance $(1.5 \mathrm{~m} \Omega$ at $\mathrm{I}>$ $25 \mathrm{kA}$ ). Second, the finite source inductance maintains a potential across an unswitched tube even when other ignitrons have fired. The latter effect is evident from the simulations shown in Figure 15, in which the closing of a start ignitron from a single $25-\mathrm{kJ}$ module is delayed $10 \mu \mathrm{s}$ from the other 39. Because of finite impedance in the modules and cables, there remains a voltage across the unswitched start ignitron of approximately $20 \%$ of the initial charge. Ignitrons develop jitter and delay problems only at very low voltages, below $0.1 \mathrm{kV}^{18}$ Therefore, for all practical charge voltages on $F R X-C$, one can expect that there will be a sufficient anodecathode potential to guarantee timely switching.

Potential fault modes are now considered. The first case is a "pre-fire" of a single crowbar ignitron in the compressor bank. This is a potentially hazardous situation because the resulting excessive current could rupture the faulty tube, spilling hot mercury into the laboratory. Circuit simulations of a crowbar prefire at $10-\mathrm{kV}$ charge are shown in Figure 16. A single tube is assumed to break down at $t=150 \mu \mathrm{s}$, along with the start tubes. The faulty crowbar tube will conduct a reverse current of $0.5 \mathrm{MA}$ for $60 \mu \mathrm{s}$. The capacitor in the bad module is responsible for
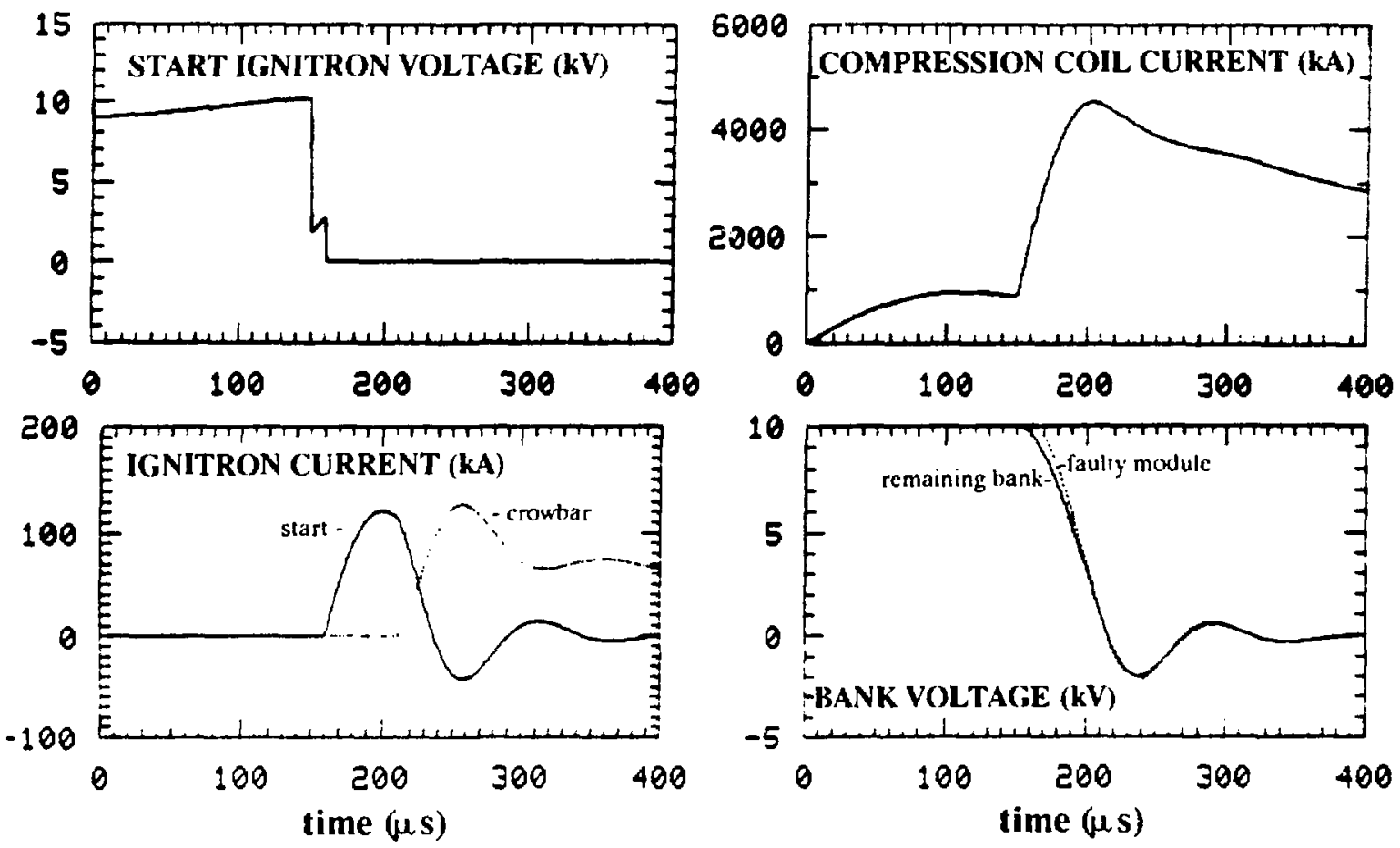

Fig. 15. Simulation in which a start ignitron in one compression module is switched $10 \mu \mathrm{s}$ after the other 39 . 

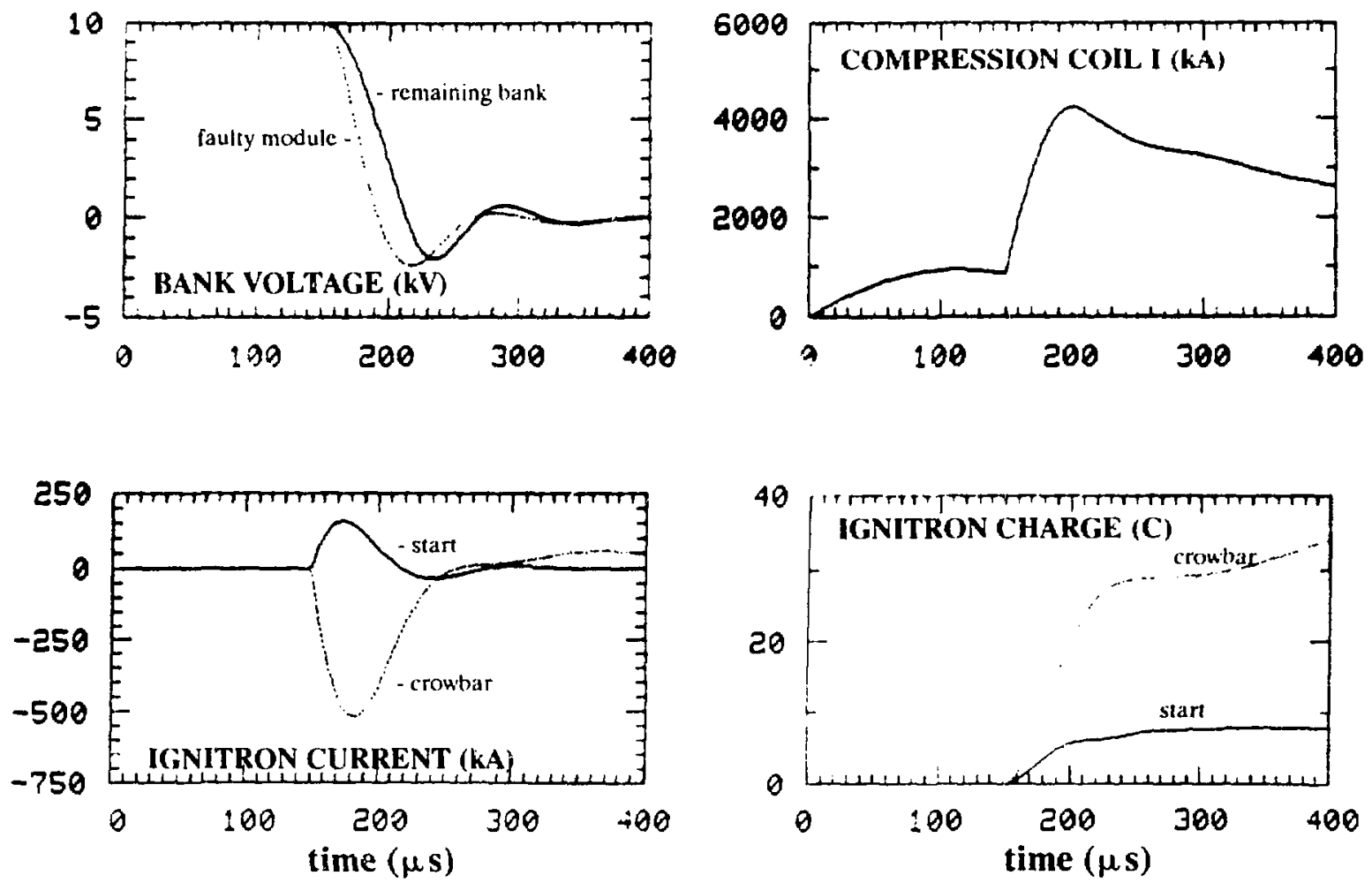

Fig. 16. Circuit fault simulation in which a single crowbar ignitron in the compression bank prefires with the start switches.

one third of the fault current, the difference coming from the remaining portion of the bank. Because of the relatively large module and cable impedance, most of the current from the other 39 modules is directed to the load. Simulations of a crowbar pre-fire in a guide-field bank module indicate a fault current of $0.4 \mathrm{MA}$, most of which comes from the $50-\mathrm{kJ}$ capacitance of the faulty module. Without the inconel series resistors, fault currents would be approximately $20 \%$ larger for both crowbar pre-fire situations.

It is relatively difficult to predict the fate of a crowbar tube that prefires. There is a limited amount of ignitron data at ultra-high current. Preliminary tests at Livermore indicate that a size-D tube will fail after six 475-kA, 168-C discharges, but will survive up to 250 discharges at $300 \mathrm{kA}$ and $102 \mathrm{C}$ before failing. ${ }^{15}$ Tubes usually failed because of ignitor wetting although in one case the anode electrode was bent $10^{\circ}$. The glass seals did not break. From the Livermore results, we mighr speculate that the ignitron will probably survive a crowbar prefire only at charge voltages below $7 \mathrm{kV}$, and that a mercury spill is unlikely to accompany any failure. However, these data must be extrapolated with caution. The crowbar prefire mode on $F R X-C$ is different from the Livermore experiments in that the fault current is reversed and.the charge transfer is small, less than $50 \mathrm{C}$. Oaly time and experiments with the $F R X-C$ system will reveal the ignitron survival rate during a crowbar prefire. Fortunately, prototype testing indicates that this mode will be highly unlikely, provided the ignitrons are conditioned (sec Section VI).

A second potential fault mode corresponds to the case where there is no crowbar. A crowbar master trigger failure can cause this fault. The simulations illustrated in Figure 17 are for a discharge with no compression bank crowbar. The capacitor voltage and the ignitron current both reverse by about $60 \%$. High-energy-density capacitors, like those used on $F R X-C$, will usually survive an occasional large voltage reversal. Manufacturers quote an empirical scaling law ${ }^{19}$ for capacitor lifetime $\mathrm{N}=\mathrm{N}_{\mathrm{R}} \times\left(\ln \mathrm{R} / \ln \mathrm{R}_{\mathrm{R}}\right)^{8 / 5}$, 

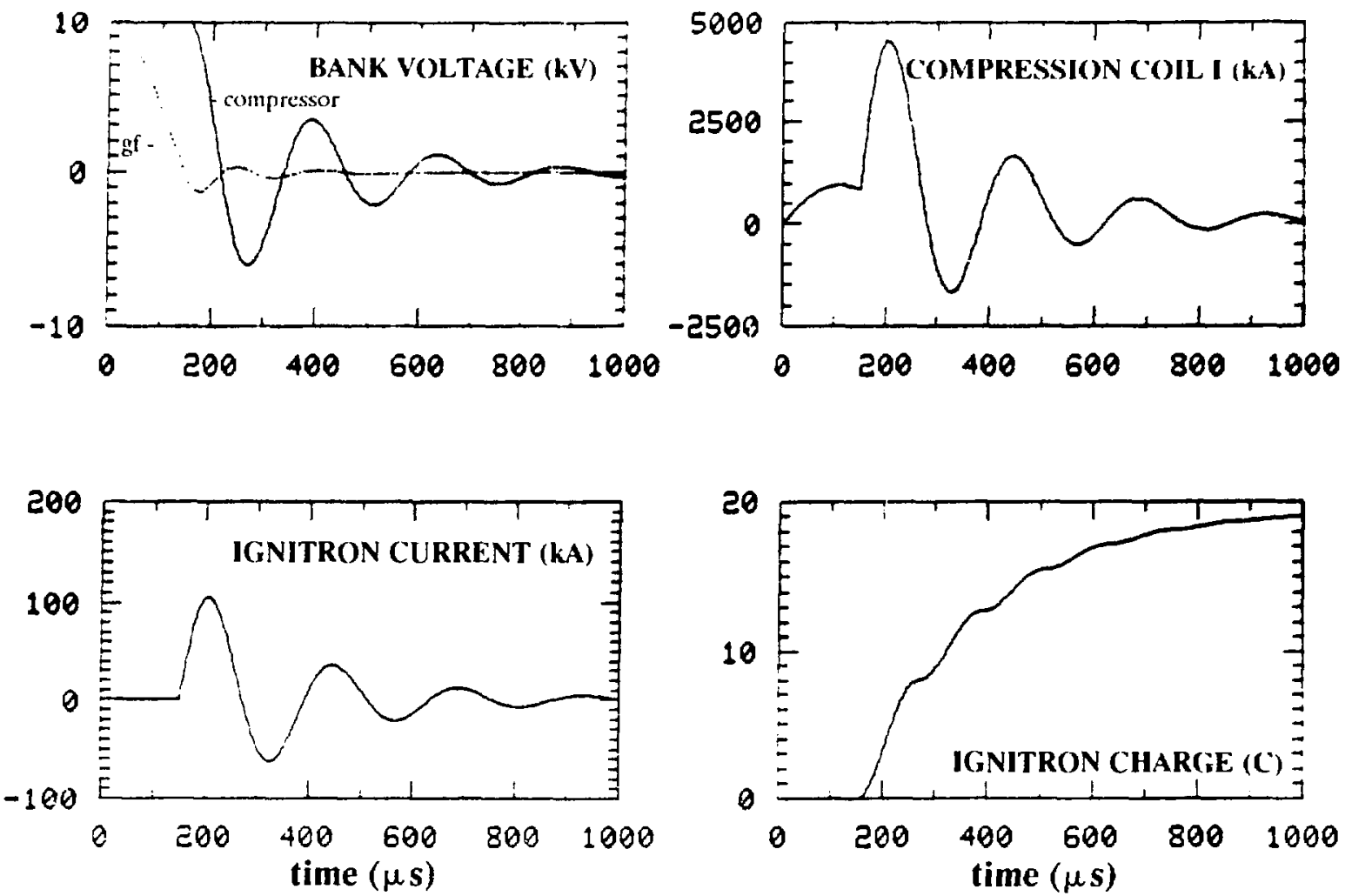

Fig. 17. Circuit fault simulation in which the compression bank is not crowbarred.

where $N_{R}$ is the shot rating for a voltage reversal of $R_{R}$, while $R$ is the actual reversal of the experiment. Applying this equation to the $F R X-C$ system where $N_{R}=10,000$ at $R_{R}=0.20$, one predicts that the capacitors should survive over 1500 discharges at $10-\mathrm{kV}$ without crowbar. Reverse current through a start ignitron is often thought to deteriorate tube performance, presumably due to graphite contamination of the mercury pool. Unfortunately there are no data available to help quantify this effect.

\section{PROTOTYPE EXPERIMENTS}

Prototype modules were built and subjected to extensive testing. Experiments were performed in the Scyllac test-bay at Los Alamos. Three 25-kJ modules were discharged up to 2000 times at full rating: $10-\mathrm{kV}$ charge voltage, $100-\mathrm{kA}$ output current. Similarly, a prototype $50-\mathrm{kJ}$ module was also discharged 150 times at its full rating. Currents through each ignitron and through a test load were measured with passively integrated
Rogowski coils. Capacitor voltages were measured during a discharge with a resistor voltage divider. Prototype ignitron trigger system tests, performed in parallel with these studies, are reported in the next section.

The 25-kJ module was tested against highvoltage breakdown in a series of "hi-pot" tests. Up to $30-\mathrm{kV}$ dc was applied across various components with a $100-\mathrm{kV}, 2-\mathrm{mA}$ dc power supply connected with a current-limiting, 50-M $\Omega$ series resistor. The high-voltage connector (cf. Appendix C, part \# 17) between the capacitor and the top busbar was removed for these tests. The boltom two busbars successfully withstood $25 \mathrm{kV}$. [Higher voltages were not applied so as to not exceed the manufacturer's voltage rating for the $N L 48 S A$ ignitron.] A breakdown, however, did occur with 28-kV applied across the top two busbars. The arc tracked along a G-10 clamp (Appendix C, part \# 11) and always terminated at a corner of the top busbar. [This problem was eliminated with a single layer of 0.8 -mm-thick, $\quad 0.15$-m-wide polyethylene wrapped around the busbars at the 
locations of the G-10 clamps. Voltages up to 40 kV were successfully withstood.] High-voltage breakdown was also observed between components and the space frame supports. With $30-\mathrm{kV}$ on the lower busbar, surface tracking developed along the G-10 support (part \# 10) between a busbar corner and a vertical support of the space frame. With $28 \mathrm{kV}$ between the middle busbar and the frame, an arc developed across the phenolic insulator plate (part \# 8) between the capacitor case and the aluminum support plate (part \# 7). The top plate and space frame successfully held off $30 \mathrm{kV}$. Finally the $Y K-198$ cable successfully withstood $25 \mathrm{kV}$ applied across the two conductors.

From the hi-pot tests one concludes that the safety factor against electrical breakdown is approximately three. This factor, while acceptable for the $F R X-C$ system, could be further improved by either adding polyethylene insulation around the busbars rear the G-10 pieces, or by adding a radius to the relatively sharp busbar corners. The middle busbar voltage should always be low, less than $2 \mathrm{kV}$; therefore, a safety factor of 14 exists against breakdown between the capacitor case and support plate.

The first 1500 discharges were with a single $25-\mathrm{kJ}$ module fired into a $3-\mu \mathrm{H}$ test load. The module current was similar to that expected on $F R X-C: I_{\max }=10 \mathrm{kA}$ per kilovolt charge, $\tau_{1 / 4}=$ $60 \mu \mathrm{s}$. Only six of the twelve output cables were connected to the module, so that each cable carried up to $17-\mathrm{kA}$, two times the design value. Both $Y K-198$ and $R G-217 / U$ cables were tested. Banana plugs used on cable inner conductor connections were also tested at $17 \mathrm{kA}$. Three parallel $R G 17 / 14$ cables were also installed in series with the other components in order to test six more banana plug connections at $35 \mathrm{kA}$. Finally, Scyllac cable cartridges, which will be used to connect output cables to the FRX-C compressor collector plates, were placed in this circuit and tested at $10-\mathrm{kV}$ and 100-kA levels. Unlike previous applications at $60-\mathrm{kV}$, there was no oil or $\mathrm{SF}_{6}$ insulation in the cartridge assemblies.

Data from a typical 10-kV discharge are shown in Figure 18. The measured $20 \%$ capacitor veltage reversal and $55 \%$ current reversal are in good agreement with the simulations shown in Figures 3 and 13. In accordance with manufacturers' recommendations, the crowbar ignitron is not triggered until there appears a forward voltage across the tube, i.e., not until a modest capacitor voltage reversal $(0.1 \mathrm{kV})$. The $55 \mu \mathrm{s}$ crowbar current risetime is principally a result of finite inductance, also consistent with the predictions.

The inconel resistor was removed for a limited number of discharges. Larger reversals in the capacitor voltage (28\%) and series ignitron current $(74 \%)$ were measured. At the time of maximum current reversal, the crowbar ignitron current dropped almost to zero. These low
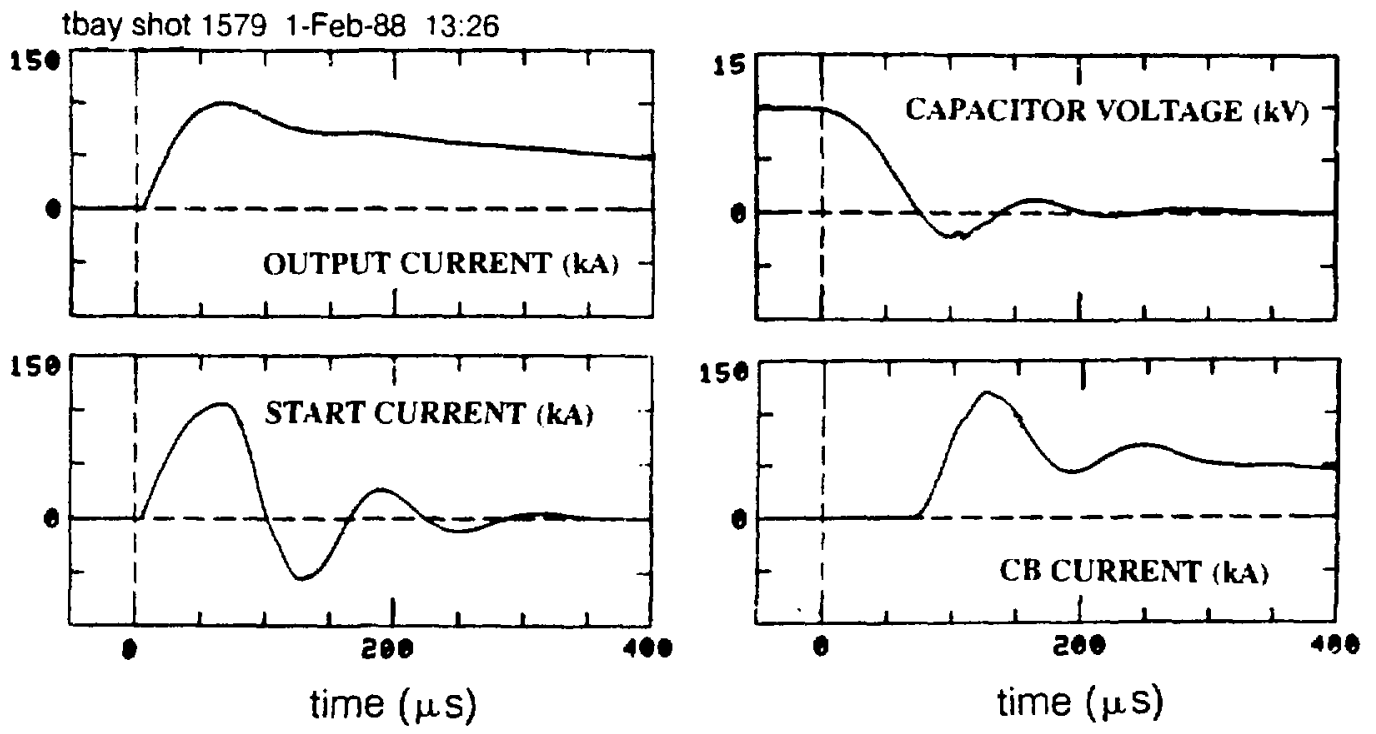

Fig. 18. Typical data measured on a prototype $25-k J$ module. 
rowbar currents are undesirable because the tube resistance increases and the arc could extinguish. The characteristic $L / R$ decay time of the output current was somewhat faster than the case with the inconel, presumably die to the increased start loop current and crowbar ignitron resistance.

The necessity for proper ignitron conditioning became immediately obvious during prototype testing. The first 50 discharges were without ignitron cooling. Because of mercury condensation near or on the anode electrode, both the start and the crowbar tube pre-fired frequently, even at voltages as low as $5 \mathrm{kV}$. As an example, data from a $10-\mathrm{kV}$ discharge with crowbar pre-fire are shown in Figure 19. This fault occurred twice during testing. Maximum fault currents through the start and crowbar tubes were 180 and $-140 \mathrm{kA}$, respectively. Good agreement with the predicted start current waveform (cf. Figure 16) was obtained. Fortunately, both ignitrons survived the crowbar pre-fire fault with no sudden drop in ignitorcathode resistance.

The ignitron pre-fire problem was eliminated by tube conditioning. The cathode temperature was maintained between $10^{\circ}$ and $15^{\circ} \mathrm{C}$ with chilled, deionized water circulated through the channel provided inside the tube jacket. After the cathode cooling system was installed, the pre-fire fault was never observed on up to 2000 discharges at full rating on every prototype module.
A trigger system failure resulted in the ringing, "no-crowbar" fault mode on at least two occasions (Figure 20). The measured reversals in voltage $(60 \%)$ and current $(70 \%)$ are in agreement with the Figure 17 simulations. From these ringing discharges, the capacitor ESR was estimated to be $11 \mathrm{~m} \Omega$. This is the largest resistance in the module circuit.

Three $25-\mathrm{kJ}$ modules were discharged in parallel into a common $0.7-\mu \mathrm{H}$ test load. Therc were approximately 120 discharges at $10-\mathrm{kV}$ charge and another 300 at $8 \mathrm{kV}$. The data in Figure 21 are from a typical $10-\mathrm{kV}$ discharge. A peak load current of over $300-\mathrm{kA}$ was measured. Inductive isolation promotes current sharing to within $\pm 25 \%$ in the three crowbar ignitrons. A more equitable distribution of the crowbar zurrent is expected on $F R X-C$ because of larger cable impedance.

The NL488A ignitrons performed satisfactorily during the prototype experiments. The ignitor-cathode resistances decreased with the number of shots at an acceptable rate. From the resistance data plotted in Figure 22, we anticipate a tube lifetime of at least 10,000 discharges at the design rating. $X$-ray photographs (see Figure 23) revealed no further deterioration of ignitron components, such as anode erosion or bending.

Eighteen YK-198 cable-connector assemblies were tested during the prototype experiments. Each assembly was routinely operated at $17-\mathrm{kA}$,
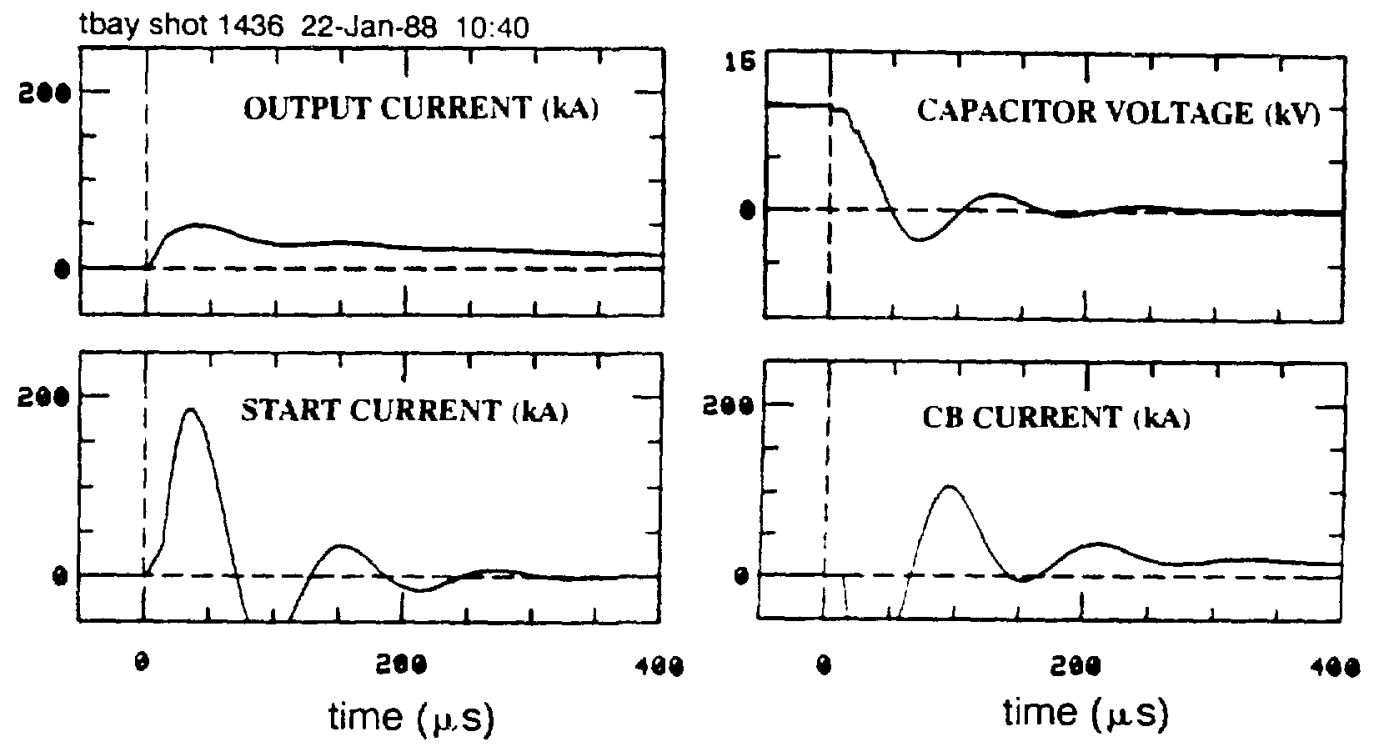

Fig. 19. Fault mode data obtained during prototype testing. The crowbar ignitron in a $25-k J$ module pre-fired at $1=12 \mu \mathrm{s}$. 
tbay shot 1772 10-Feb-88 10:02
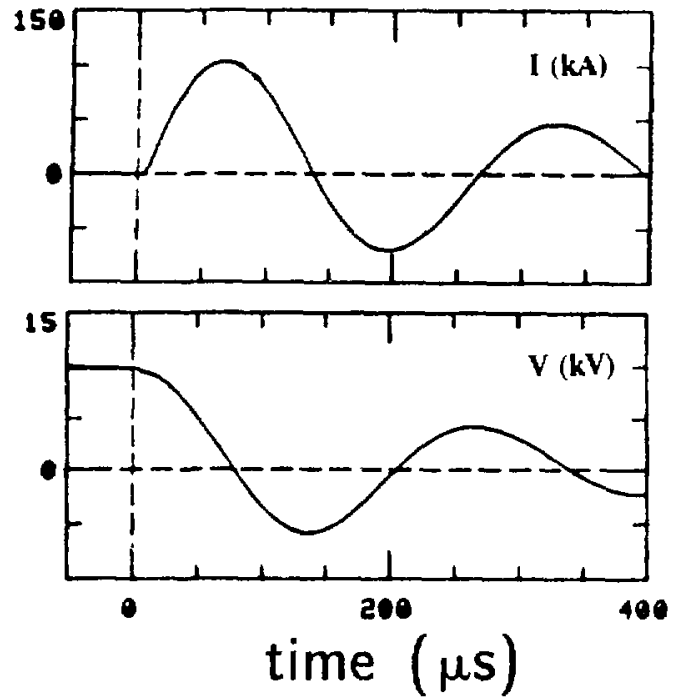

Fig. 20. Fault-mode data obtained during prototype testing. A $25-\mathrm{kJ}$ module is discharged without a crowbar. two-times the design value. The cable performed satisfactorily throughout the tests. Provided they were carefully prepared and installed, connectors did not deteriorate. There was evidence of arcing at the banana plug connections when the plug diameters were undersized. Erosion was obscrved in both the aluminum module busbar and in the brass cable cartridge plate. When the plug diameter was sufficiently large to ensure a tight fit, there was no evidence of arcing, even for 1000 discharges at 33-kA per connecior.

One 50-kJ prototype module was discharged into a $6 \mu \mathrm{H}$ test load for over 140 discharges at $10 \mathrm{kV}$ and $100 \mathrm{kA}$, and for 65 at $8 \mathrm{kV}$ and $80 \mathrm{kA}$. Typical data are plotted in Figure. 24. The only major difference from the $25-\mathrm{kJ}$ waveform $: \mathrm{s}$ the longer pulse, $\tau_{1 / 4}=110 \mu \mathrm{s}, L / R=1.50 \mathrm{~ms}$.

The 50-kj prototype system performed satisfactorily during these tests with two exceptions. First, minor arcing developed on the series resistcr at the soldered junction between the inconel strips and the OFHC copper tabs. The

\section{tbay shot 3049 11-May-88 :5:48}
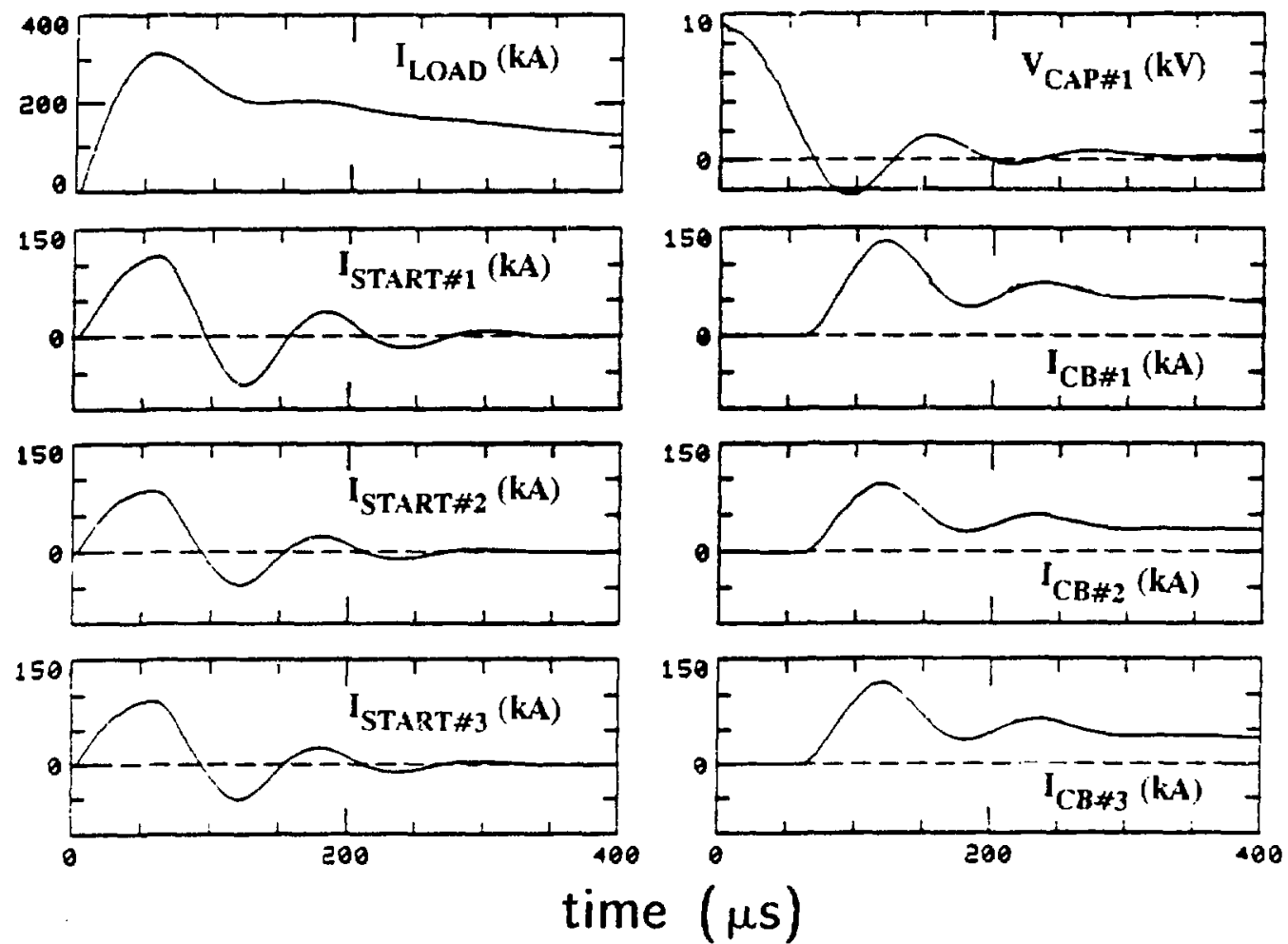

Fig. 21. Typical data for three $25-\mathrm{kJ}$ modules, discharged in parailel into a common luad. 


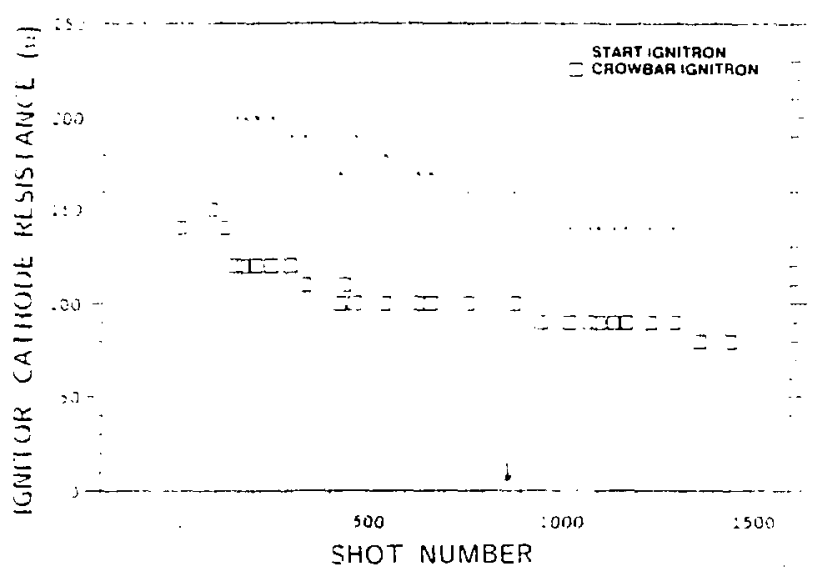

Fis. 22. Variation of ignitor-cathode resistance with the number of $10 \mathrm{kV}, 100-\mathrm{kA}$ discharges for a prototype $25-\mathrm{kJ}$ modult. The arrow at shot number 880 corresponds to the time when a high-voltage diode was removed from the ignitor trigger circuit.
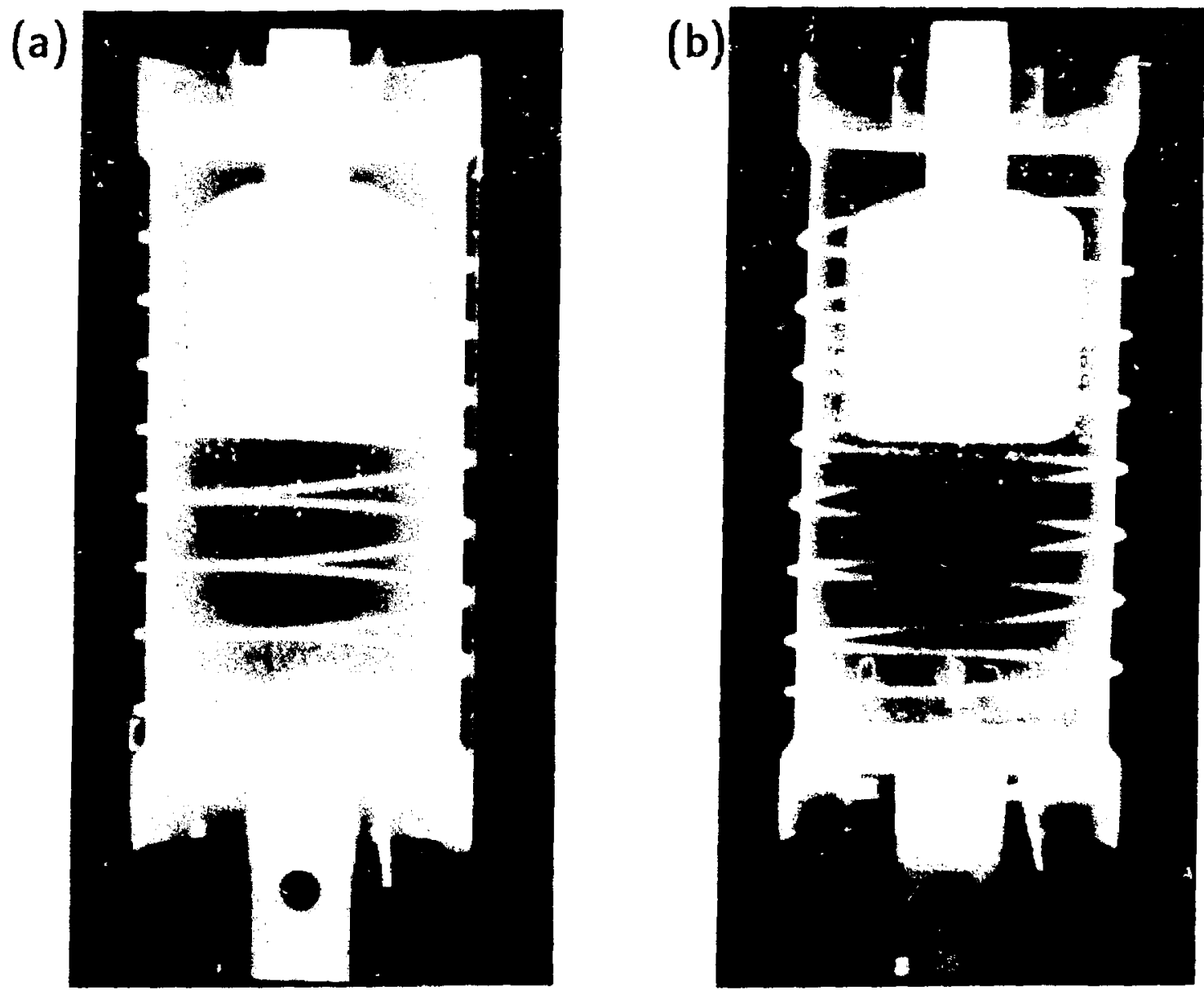

Fig. 23. Radiographs of a (a) start and (b) crowbar ignitron after more than 2,000 discharges. 


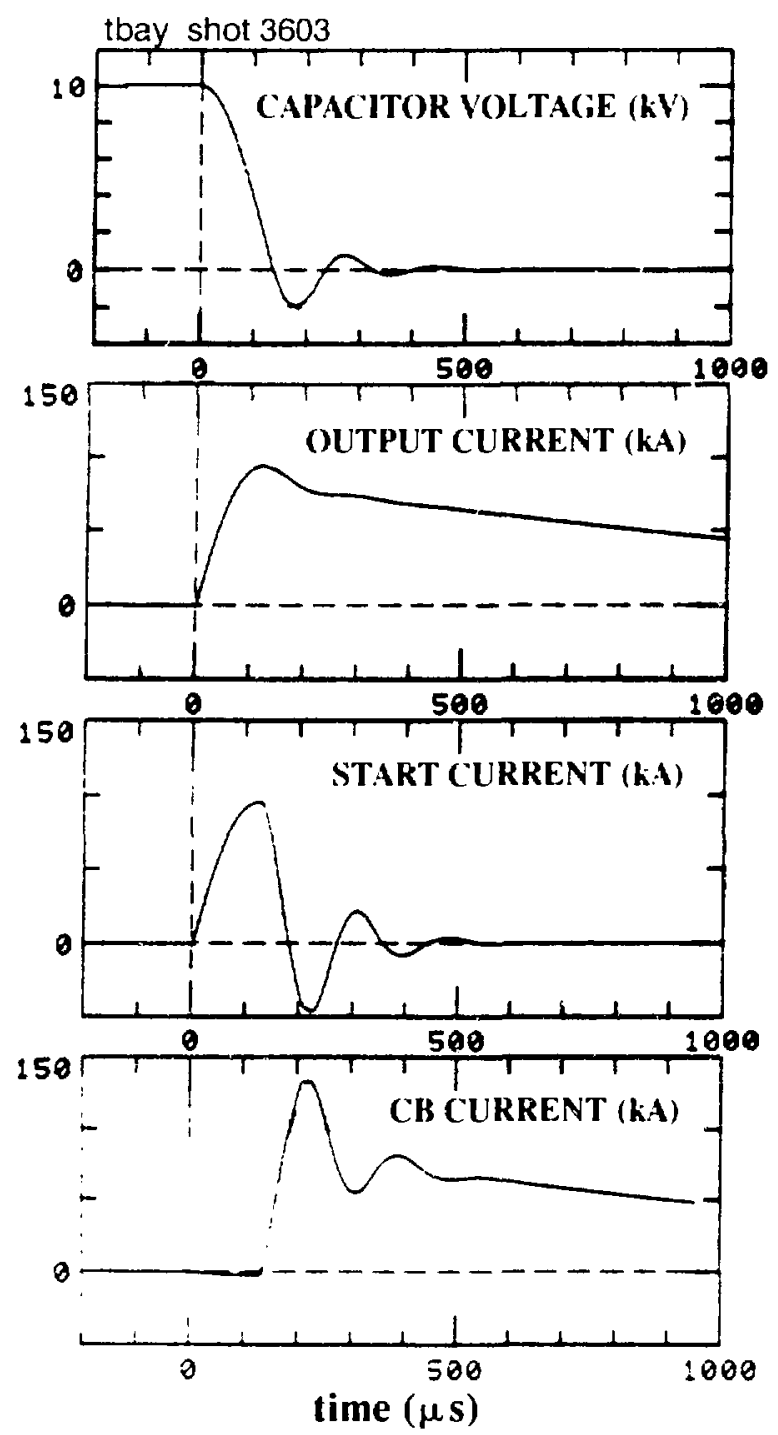

Fig. 24. Typical data obtained with the $50-\mathrm{kJ}$ prototype module.

resistors with the welded nickel tabs, on the other hand, performed flawlessly. Therefore, the nickel/inconel resistors have been chosen for all modules.

The second problem involved a rapid deterioration of the crowbar ignitor. During these tests, the ignitor-cathode resistance dropped monotonically from $240 \Omega$ to 0 . The pulse decay time was substantially longer than that expected on FRX-C; consequently, about $130 \mathrm{C}$ of charge is transferred through the crowbar tube, a value well above the 70-C design limit. Fortunately, however, less than $50 \mathrm{C}$ is expected during normal operation on $F R X-C$; therefore, tube deterioration is not expected there. An interesting observation related to this second failure is that the crowbar ignitor could be resuscitated by "trigger conditioning." Following a technique developed at the Physics International Corporation, ${ }^{20}$ the wetted ignitor was energized approximately 100 times by the $700-A, 4 \mu \mathrm{s}$ trigger pulse. [The trigger system is described in the next section.] No voltage was applied between the anode and cathode. The ignitor resistance increased to approximately $10 \Omega$ after 30 pulses, reaching $30 \Omega$. after 100 pulses.

\section{TRIGGER SYSTEM}

A dependable trigger system is essential for the proper operation of the 100 size-D ignitrons in the $F R X-C$ compressor system. As with the modules, an extensive prototype evaluation program was implemented before the design was finalized.

According to manufacturer's specifications, the open-circuit voltage for the ignitron trigger should range between 1.5 and $3.0 \mathrm{kV}$, and must never reverse more than $5 \mathrm{~V}$. In addition, the short-circuit igmitor current should range between 100 and $250 \mathrm{~A}$ and with a pulsewidth between 3 and $7 \mu \mathrm{s}$ FWHM. Over the years, however, ignitron users have found improved tube performance with trigger voltages and currents greater than the specification. For example, experiments with $4-\mathrm{kV}, 500-\mathrm{A}$ trigger pulses indicate reliable firing, low jitter, and little ignitor deterioration. ${ }^{21}$ The FRX-C trigger system was, therefore, designed around the latter, more energetic parameters.

On FRX-C there are four independent trigger subsystems: guide-field start, guide-field crowbar, compression-field start, and compression-field crowbar. As illustrated in Figure 25, a subsystem consists of modular units connected in parallel to a single master switch. The principal components of a trigger unit are a $0.5 \mu \mathrm{F}, 5-\mathrm{kV}$ capacitor (manufactured by $\mathrm{Hi}$ Voltage Components Inc., Largo, Florida), a 1:1 isolation transformer, and a $5 \Omega$ current-limiting resistor. There is one trigger unit for every size-D ignitron. The modular design promotes equal distribution of ignitor current. A disadvantage of 


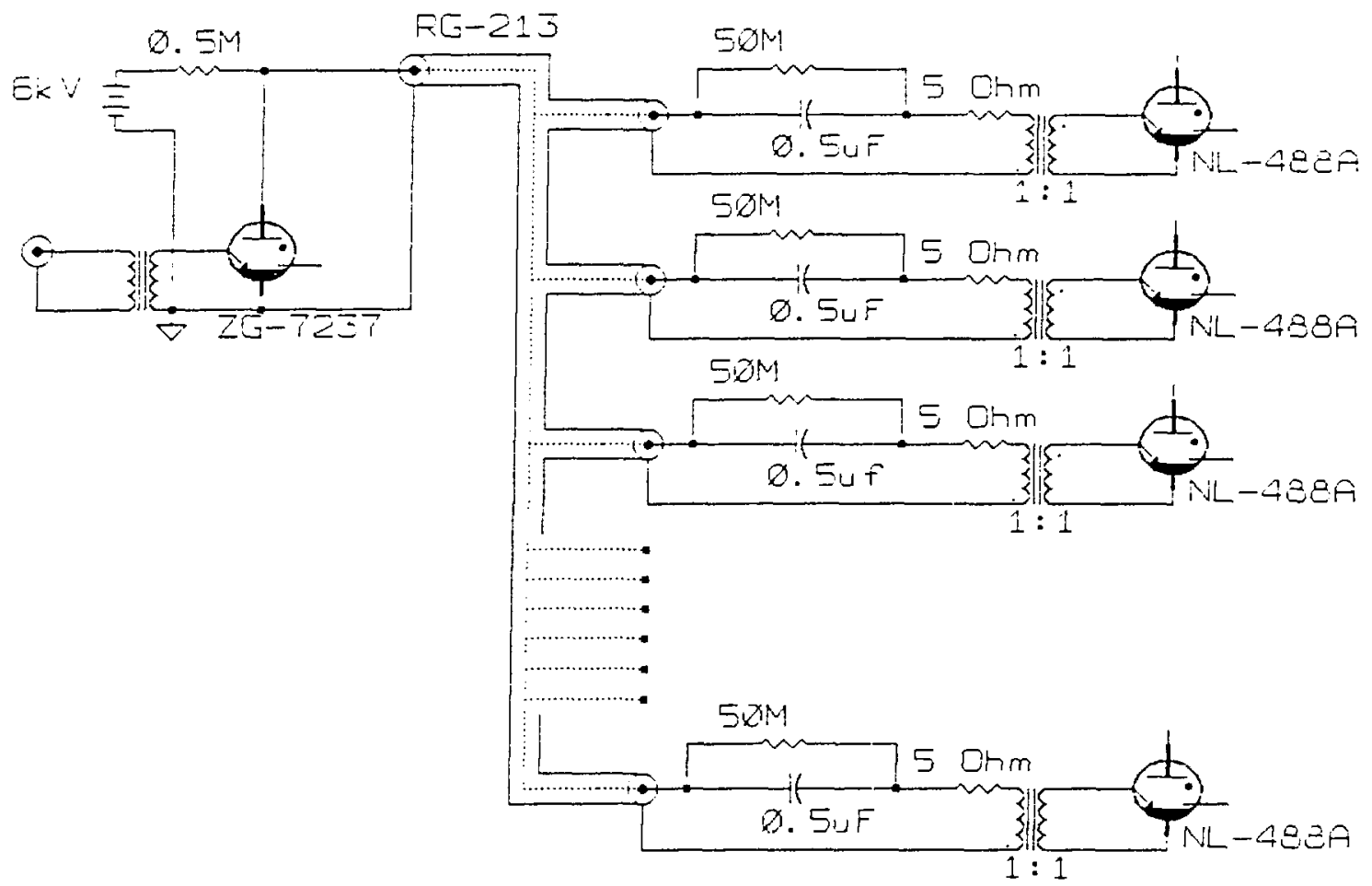

Fig. 25. Circuit diagram for an FRX-C ignitron trigger subsystem.

the desiga is the increased risk of a pre-fire caused by a high-voltage breakdown in the dc-charged cables and connectors. Careful installation and maintenance is necessary to insure against this fault. A size-A ignitron is used for the master switch. A crowbar unit and a start unit are mounted together (see Figure 26) and installed inside a shielded trigger box. The trigger box is in turn mounted onto a capacitor bank module frame as shown in Figure 11.

Prototype trigger units were tested along with the 25 and 50-kJ modules. Ignitor currents were measured with self-integrating current transformers, and voltages were measured with a resistor divider. With the $0.5 \mu \mathrm{F}$ trigger capacitor charged to $6.2 \mathrm{kV}$, the open-circuit trigger output voltage and short-circuit current were measured to be $6 \mathrm{kV}$ and $0.7 \mathrm{kA}$, respectively. The typical ignitor current waveform shown in Figure 27 was measured during a $10-\mathrm{kV}, 100-\mathrm{kA}$ module discharge. A peak current $0.65 \mathrm{kA}$ is observed with risetime and FWHM pulse-width of 1.8 and $4 \mu \mathrm{s}$, respectively.

The relatively long trigger risetime is a consequence of the large trigger capacitance and source inductance. Fortunately, this risetime is acceptable for the $F R X-C$ application. Ignitrons normally require an equally long time to establish an arc; moreover, the system will properly function even if there is several microseconds of jitter between the firing of parallel tubes ( $c$ f. Fig. 15 and accompanying discussion in Section V). For other applications, the risetime could be shortened with a smaller trigger capacitor at the expense of a reduced ignitor current (see Fig. 28).

The 1:1 transformer isolates the trigger components from the $10-\mathrm{kV}$ applied to the ignitor when the ignitron conducts. Fifteen turns of coaxial, "detonator" cable (Belden YR-2143] or equivalent, 4.9-mm o.d., $Z=31 \Omega$ ) are wound partially on a 34-mm-i.d., 70-mm-o.d., 51-mm-long ferrite core (cf. Figure 26). The outer braid of the 


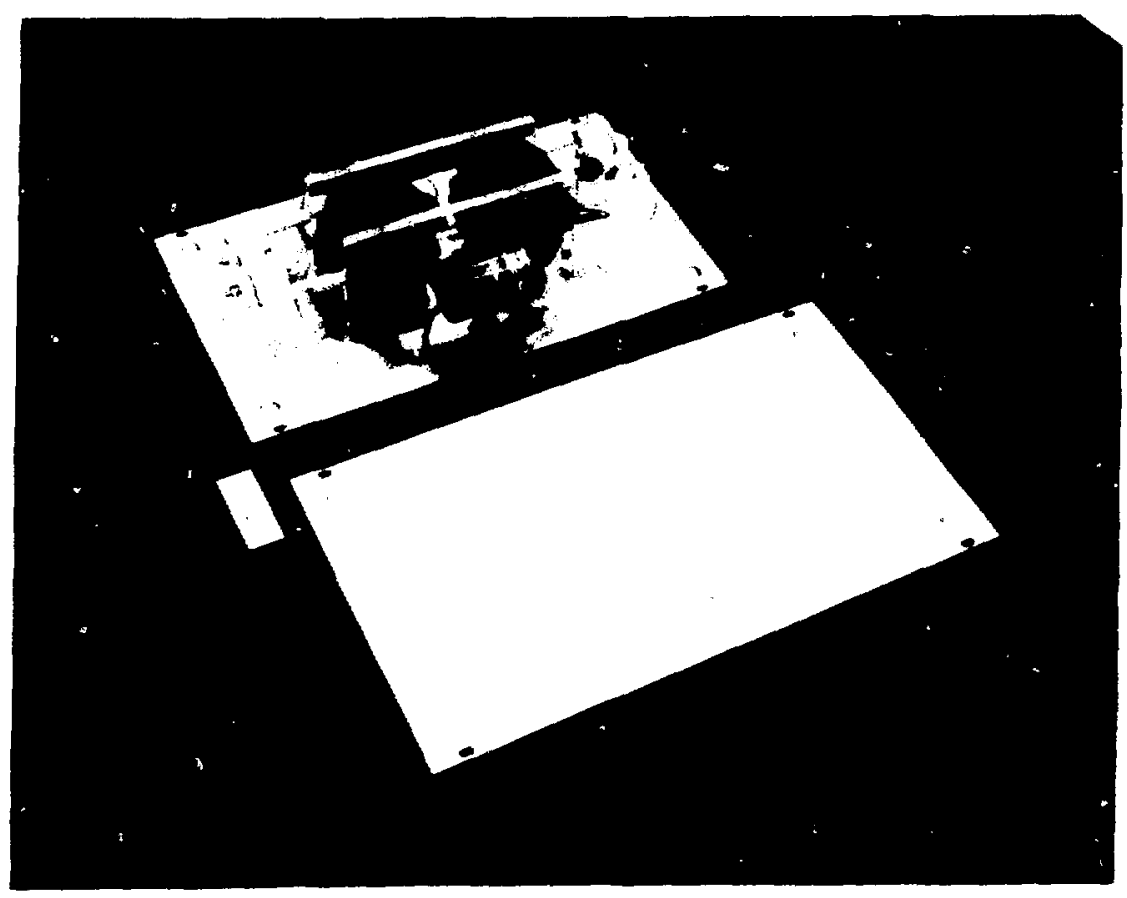

Fig. 26. Two ignitron trigger units mounted for a shielded box.

tbay shot 3553

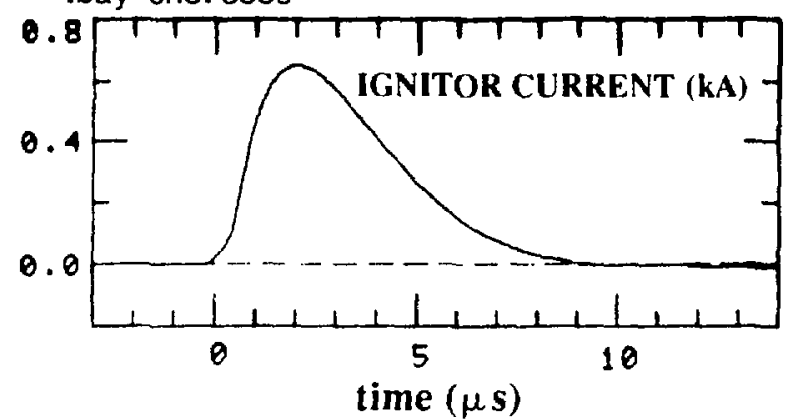

Fig. 27. Ignitor current measured during a $10-k \mathrm{~V}$ discharge.

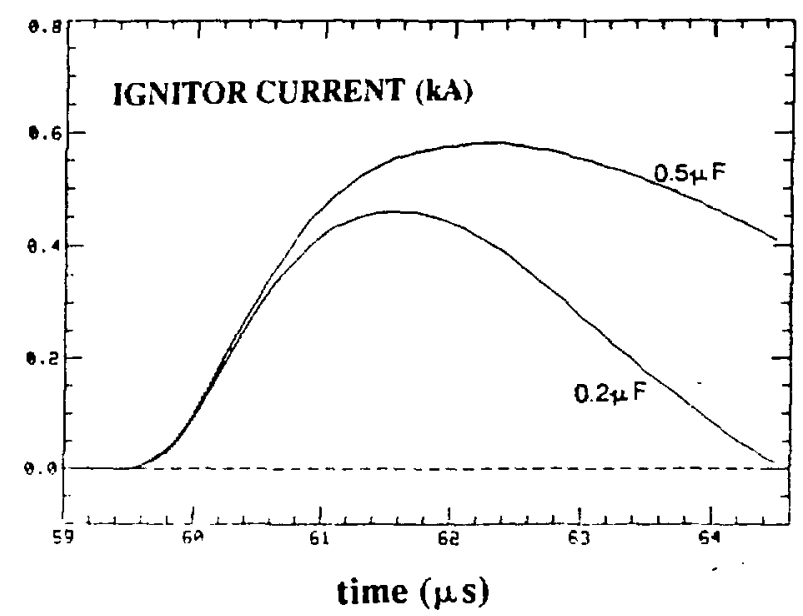

Fig. 28. Effect of trigger capacitance: crowbar ignitor cursent pulses with $0.2 \mu F$ and $0.5 \mu \mathrm{F}$ capacitors charged at $6 \mathrm{kV}$. 


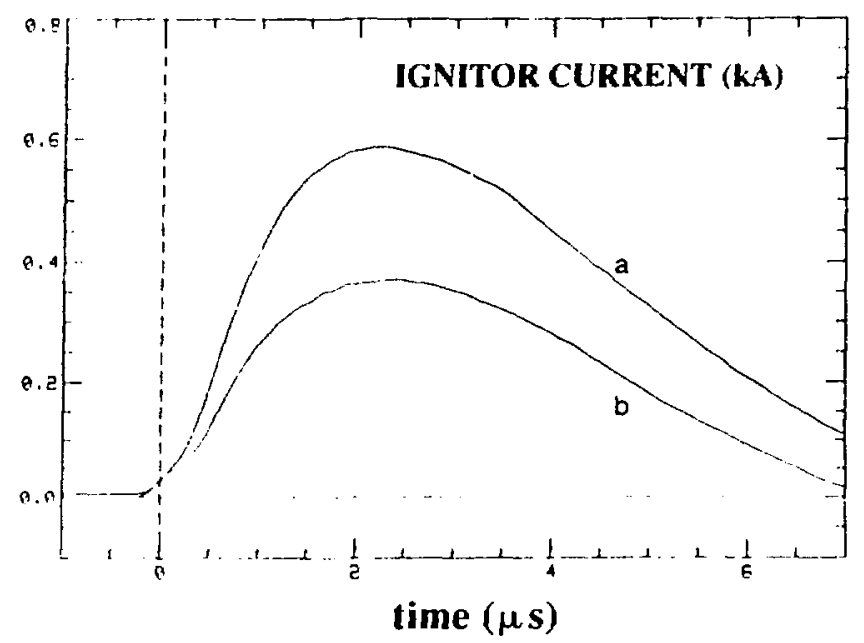

Fig. 29. Effect of isolation transformer design: measured ignitor current pulses for (a) coax and (b) non-coax transformers.

coax is used for the pririary, the center conductor for the secondary. Alternate designs were considered. For example a transformer made from 10 turns of $20-\mathrm{kV}, 18$-awg wire on the same ferrite core was found less efficient than the coax (see Figure 29).

A $5 \Omega$ resistor is placed in series with each isolation transformer ( $c f$. Figure 25). The purpose of this resistor is twofold. First, it limits the ignitor current during the tube conduction phase. Second, it damps the trigger pulse, eliminating ignitor current reversal. Ignitors can be ruined by reversed trigger currents; however, as discussed below, this is only a potential problem when the tube is nonconducting (e.g., when one applies a trigger pulse to a tube with no anode-cathode voltage). ${ }^{21}$ The effect of the resistor value on the ignitor pulse is shown in Figure 30. The ignitor current decreased by approximately a factor of two when the limiting resistance was increased from 0 to $10 \Omega$. These tests were performed with the $0.2 \mu \mathrm{F}$ trigger capacitor charged at $6 \mathrm{kV}$. The ignitor pulse was critically damped with the $4.7 \Omega$ resistance. This optimum value was chosen for the $F R X-C$ system since reversal was eliminated with minimum reduction in the ignitor current.

Ignitor current reversal does not appear to be detrimental to ignitrons during a discharge. When a tube conducts, a small fraction $(\leq 0.3 \%)$ of the main current is often induced in the ignitor circuit. As seen from the data in Figure 31, the induced ignitor current can be as large as $-280 \mathrm{~A}$.

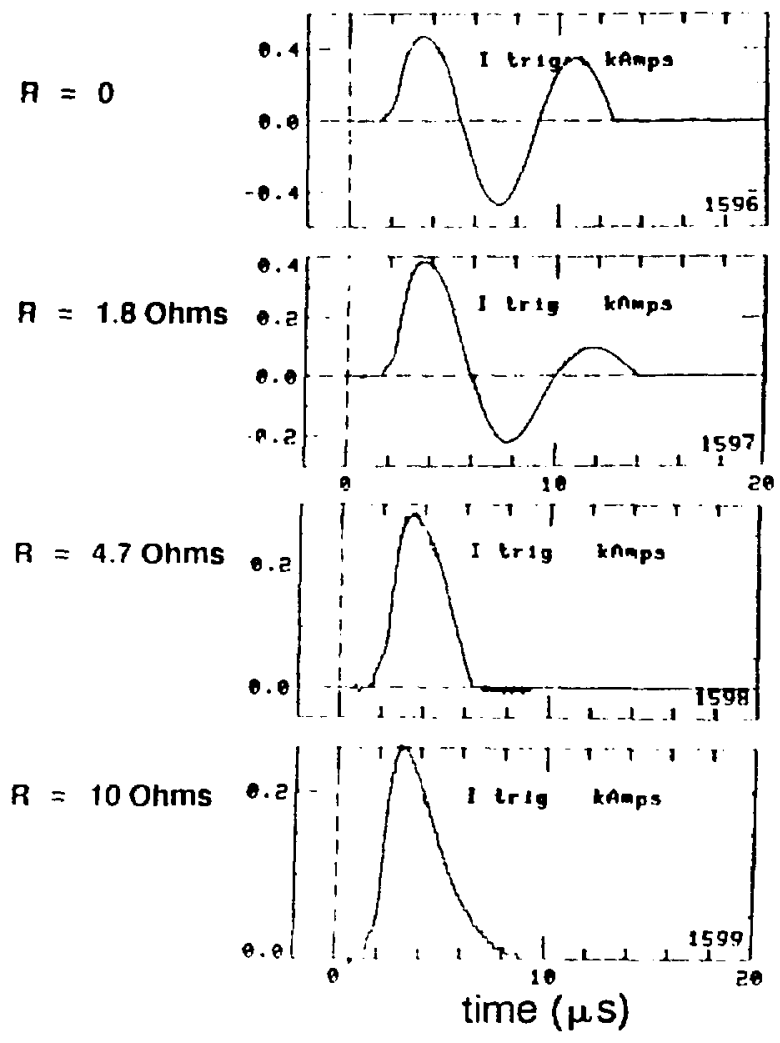

Fig. 30. Effect of the current-limiting resistor in the trigger circuil: measured ignitor current pulses are plotted vs lime. Each trace corresponds to a different limiting resistance. 
Ignitor current

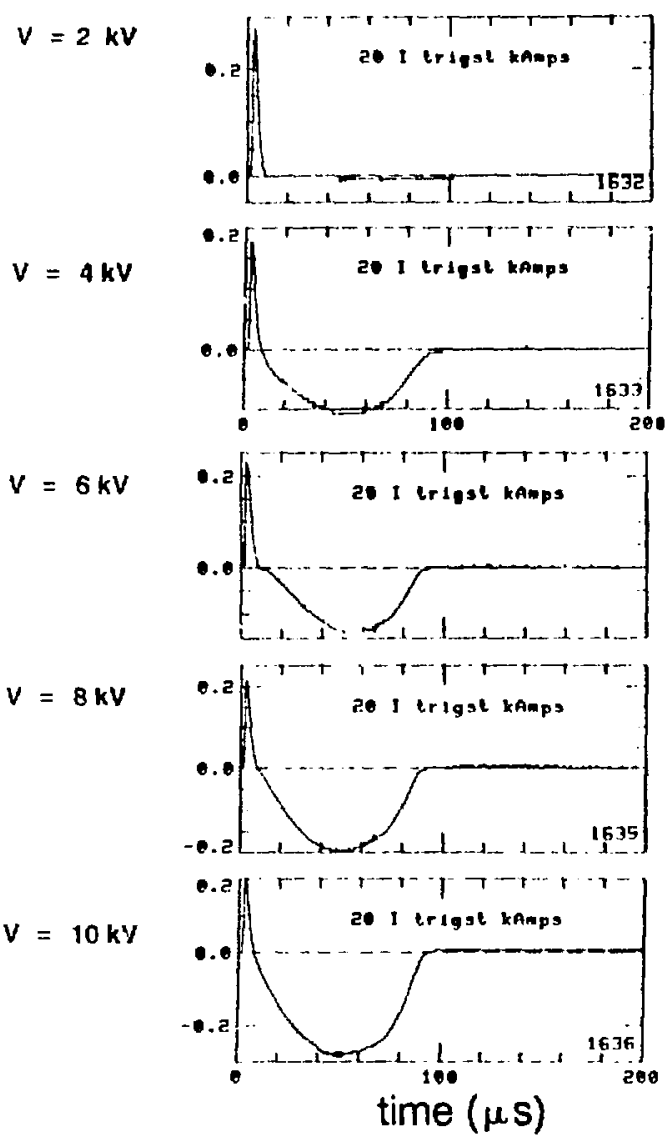

Ignitron current
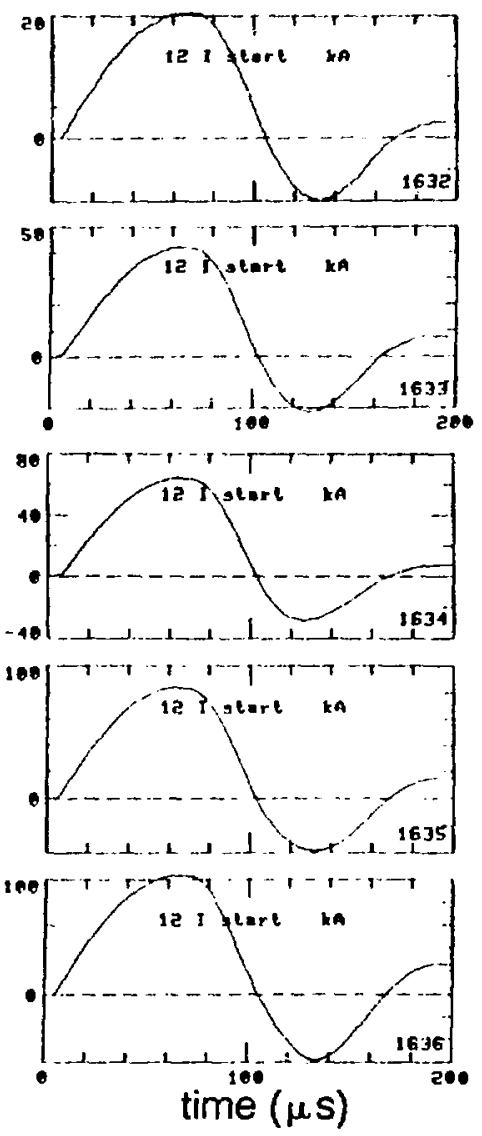

Fig. 31. Ignitor current reversal measured during a discharge. Both the ignitor and start ignitron current waveforms are plotted. A $25-\mathrm{kJ}$ module was discharged at voltages between 2 and $10 \mathrm{kV}$.

The reversed ignitor current magnitude is comparable to that of the trigger pulse but the pulsewidth is ten-times longer. This current was eliminated by a high-voltage diode piaced in series with the isolation transformer secondary. The diode, however, proved unnecessary during prototype testing. This conclusion is supported by the Figure 22 data in which the first 880 shots were with the diode, the remainder without. There was no discernible difference in the decay of ignitor resistance with or without the diode.

\section{ACKNOWLEDGMENTS}

The design and prototype evaluation of the $F R X-C$ compressor pulsed-power system took two years to complete. In this period we benefited from discussions with many experts from the pulsed-power community. It is with pleasure that we gratefully acknowledge the following people who provided useful recommendations, frank criticism, and unpublished test data: R. F. Gribble, I. Henins, E. Kemp, J. Melton, W. Reass, A. Schofield, and R. Slice (Los Alamos National Laboratory), D. Larson, K. Whitham, D. B. Cummings, and R. Kihara (Lawrence Livermore National Laboratory), H. Aslin (Physics International Corp.), C. B. Dobbic and A. Ramrus (Maxwell Laboratories), K. F. McDonald and E. A. Crawford (Spectra Technologies, Jnc.), A. P. Shulski (Richardson Electronics), R. J. Seddon (English Electric Valve Lid.), D. Nichols (General Electric Corp.), F. MacDougal (Aerovox, Inc.), and L. Bayes (Belden Wire and Cable Co.). 


\section{REFERENCES}

1. M. Tuszewski, R. E. Chrien, E. J. Yavornik, W. T. Armstrong, et al., "The FRX-C Large Source Modification," in Proceedings of the 7th Symposium on the Physics and Technology of Compact Toroids in the Magnetic Fusion Enengy Program, A. R. Sherwood, Ed., Los Alamos National Laboratory report LA10830-C (September 1986), pp. 152-154.

2. D. J. Rej, "Design and Construction Details of the FRX-C/T Device: A Compact Toroid Plasma Translation Experiment," Los Alamos National Laboratory report LA-10108-MS (August 1984).

3. R. L. Hagenson and R. A. Krakowski, "A Compact-Toroid Fusion Reactor (CTOR) Based on the Field-Reversed Theta-Pinch," in Fusion Reactor Design and Technology (IAEA, Vienna, 1983), Vol. I, pp. 377-390.

4. K. Bol, V. Arunasalam, M. Bitter, D. Boyd, et al., "Radiation, Impurity Effects, Instability Characteristics and Transport in Ohmically Heated Plasmas in the PLT Tokamak," in Plasma Physics and Controlled Nuclear Fusion Research 1978 (IAEA, Vienna, 1979), Vol. I, pp. 11-33.

5. R. E. Siemon, R. E. Chrien, W. N. Hugrass, S. Okada, et al., "Field-Reversed Configuration Experiments," in Plasma Physics and Controlled Nuclear Fusion Research 1988 (LANL preprint LA-UR 88-2878, to be published by the IAEA, Vienna).

6. R. F. Gribble, Los Alamos National Laboratory, personal communication, April 1987.

7. R. E. Chrien, "Field-Reversed Configuration Translation into a Compression Coil," The Physics of Fluids 28, 3426-3429 (1985).

8. R. L. Spencer, M. Tuszewski, and R. K. Linford, "Adiabatic Compression of Elongated Field-Reversed Configurations," The Physics of Fluids 26, 1564-1568 (1983).
9. W. T. Armstrong, R. K. Linford, J. Lipson, D. A. Platts, and E. G. Sherwood, "FieldReversed Experiments on Compact Toroids," The Physics of Fluids 24, 2068-2089 (1981).

10. F. H. Coensgen, W. F. Cummings, and A. E. Sherman, "Multistage Magnetic Compression of Highly Ionized Plasma," The Physics of Fluids 2, 350-361 (1959).

11. P. M. Bellan, "Spontaneous, Three-Dimensional, Constant-Energy Implosion of Magnetic Mirror Fields," Physical Review Letters 43, 858-861 (1979).

12. H. Meuth and F. L. Ribe, "Excitation and Damping of Compressional Hydromagnetic Waves on a Magnetized, High-Pressure Plasma Column," The Physics of Fluids 29, 3036-3051 (1986).

13. A. G. Es'kov, N. P. Kozlov, R. Kh. Kurtmullaev, V. N. Semenov, V. I. Khvesyuk, and A. V. Yaminskii, "Energy Balance in a System With Quasispherical Liner Compression," Soviet Technical Physics Letters (English translation by the American Institute of Physics) 9, 16-17 (1983).

14. K. Whitham, D. Larson, B. Merritt, and D. Christie, "Nova Pulse Power Design and Operational Experience," Lawrence Livermore National Laboratory report UCRL95051 (January 1987).

15. R. Kihara, "Evaluation of Commercially Available Ignitrons as High-Current HighCoulomb Transfer Switches," in Proceedings from the Sixth IEEE Pulsed-Power Conference (IEEE, New York, 1987), p. 581.

16. L. Bayes, Belden Wire and Cable Co., personal communication, January 1988.

17. R. J. Seddon, English Electric Valve Ltd., personal communication, April 1987.

18. D. B. Cummings, Lawrence Livermore National Laboratory, personal communication, March 1987. 
19. C. B. Dobbie, Maxwell Laboratories, Inc., personal communication, May 1987.

20. H. Aslin, Physics International Corp., personal communication, March 1987.

21. A. P. Shulski, Richardson Electronics, Inc., personal communication, March 1988. 
APPENDIX A: COST OF A 25-KJ MODULE

In 1987-88, the price for a single $25-\mathrm{kJ}$ module, excluding design and prototype development, was approximately $\$ 5,000$. Costs are based on quantity purchases for $\mathbf{4 0}$ complete $25-\mathrm{kJ}$ and ten complete $50-\mathrm{kJ}$ assemblies plus spare components. An itemized cost list follows:

ITEM:

CAPACITOR

IGNITRON

FLEXIBLE LEAD

CAGE

BUSBARS

G-10 SUPPORTS

FRAME

TRIGGER SYSTEM

HARDWARE

INCONEL RESISTOR $\quad 10.43$

FABRICATION

TOTAL

\section{CosT:}

$\$ 813.00$

975.00 (2 each)

20.06 (4 each)

148.47 ( 2 each)

168.93

296.94

192.07

275.40

55.45

895.71

$\$ 5035.11$ 


\section{APPENDIX B: CIRCUIT MODEL}

We now present the FRC-circuit model used in the simulations of Section II. As illustrated in Figure B1, the FRC is assumed to be already translated and trapped within a compression coil. The plasma separatrix is modeled as a fluxexcluding cylinder of radius $r_{s}$ and length $z_{s}$, located coaxially inside a cylindrical coil of radius $r_{c}$ and length $z_{c}$. The FRC and the compression coil are elongated so that end effects can be ignored. The magnetic flux $\phi_{e}(t)$ is constant along the inner surface of the compression coil and it is zero at the plasma separatrix. The relationship between $\phi_{e}$ and the coil current $I$ is obtained with Ampere's law,

$$
\left.I=\mid \phi_{e} z_{c} / \pi r_{c} \mu_{o}\right] \times\left[1+x_{z} x_{s}^{2} /\left(1-x_{s}^{2}\right)\right]
$$

where $x_{s}=r_{s} / r_{c}, x_{z}=z_{s} / z_{c}$, and $\mu_{o}$ is the permeability of free space. The inductance of this system, $L=\phi_{e} / I$, can then be written as

$$
\mathrm{L}=\mathrm{L}_{\mathrm{v}} /\left[1+\mathrm{x}_{\mathrm{z}} \mathrm{x}_{\mathrm{s}}^{2} /\left(1-\mathrm{x}_{\mathrm{s}}^{2}\right)\right]
$$

where $L_{v}=\mu_{c} \pi r_{c}^{2} / z_{c}$ is the coil inductance without plasma.
A simplified version of the Figure 2 circuit is used in this model. The plasma and compression coil are modeled as a single time-dependent inductance $\mathrm{L}$ given by $\mathrm{Eq}$. B2. The guide-ficld bank is assumed crowbarred at time $\mathrm{t}=0$, and an initial guide-field flux $\phi_{\mathrm{e}}(0)>0$ is assumed present. The initial currents in the compression coil and isolation inductor are adjusted to meet this condition. In the simulations, changes in $x_{s}$ and $x_{z}$ are computed self-consistently with the circuit equations using Eq. B1 and the adiabatic scaling laws derived in Reference 8 . Two extreme FRC equilibria, corresponding to the high and low-flux sharp boundary models, - -e considered. Plasma losses are ignored.

The coupled circuit and plasma equations are solved numerically for initial conditions that simulate an FRC plasma translated into the $F R X$ $C$ compression coil: $\phi_{\mathrm{c}}=30 \mathrm{mWb}, \mathrm{r}_{\mathrm{s}}=0.16 \mathrm{~m}$, $x_{s}=0.7, z_{s}=2.2 m, x_{z}=0.7$. The compression bank start switch is closed at time $t=0$, the crowbar at $\mathrm{t}=60 \mu \mathrm{s}$. The solutions are plotted in Fig. 5.

It is interesting to examine other aspects of compression heating and FRC equilibria in terms of the electric circuit. The magnitude of the coil voltage is given by the relationship,

$$
V_{\text {coil }}=L(d I / d t)+I(d L / d t)
$$

\section{FLUX CONSERVING COIL}

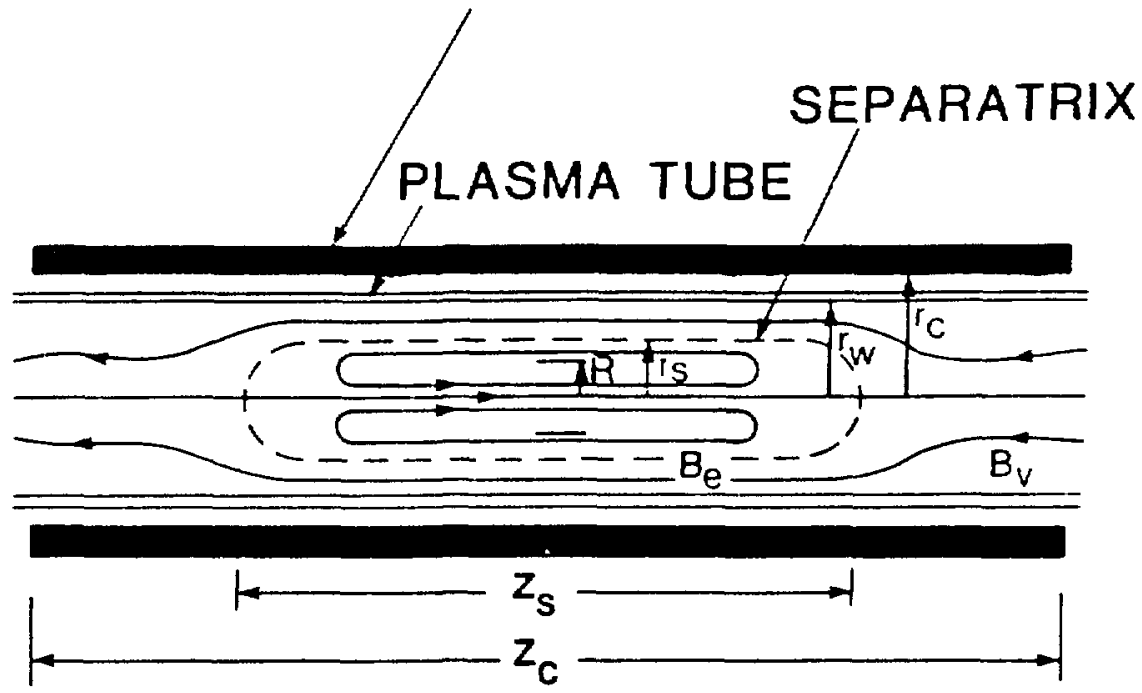

Fig. B1. FRC geometry used in the circuit simulations. 
The last term in Eq. B3 corresponds to the change in load inductance that occurs when the plasma is compressed. This term represents dissipation corresponding to the work done by the circuit in compressing the plasma. In other words, the $\mathrm{dL} / \mathrm{dt}$ term acts as an effective resistance. Multiplying Eq. B3 by I and rearranging terms the total power deposited to the load is

$$
P_{\text {coil }}=1 / 2 L\left(d l^{2} / d t\right)+I^{2}(d L / d t) .
$$

After integrating Eq. B4 over time and rearranging terms, the total energy is

$$
E_{t O t}=1 / 2 L I^{2}+1 / 2 \int I^{2}(d L / d t) d t .
$$

The first term in Eq. B5 corresponds to the Bfield energy $E_{B e}$ outside the plasma separatrix. This fact is readily seen by combining Eq. B1 with the following straightforward relationship for $E_{B e}$ :

$$
\mathrm{E}_{\mathrm{Be}}=\left(\phi_{\mathrm{e}}^{2} \mathrm{z}_{\mathrm{c}} / 2 \mathrm{r}_{\mathrm{c}}^{2} \pi \mu_{\mathrm{o}}\right) \times\left[1+\left(\mathrm{x}_{\mathrm{s}}^{2} \mathrm{x}_{\mathrm{z}}\right) /\left(1-\mathrm{x}_{\mathrm{s}}^{2}\right)\right]
$$

or, alternately,

$$
\mathrm{E}_{\mathrm{Be}}=\mathrm{E}_{\mathrm{Bv}} \times\left[1+\mathrm{x}_{\mathrm{s}}^{2} \mathrm{x}_{\mathrm{z}} /\left(1-\mathrm{x}_{\mathrm{s}}^{2}\right)\right],
$$

where $E_{B v}$ is the field energy for vacuum conditions, i.e., for the same $\phi_{c}$ but with no plasma. Combining radial pressure balance and the average beta condition, $\beta=1-1 / 2 x_{s}{ }^{2}$, the energy $E_{\text {int }}$ within the separatrix (both magnetic and plasma thermal) can be expressed in terms of $E_{B v}$ by the following relationship

$$
E_{\text {int }}=E_{B v} x_{s}^{2} x_{z}(1+\beta / 2) /\left(1-x_{s}^{2}\right)^{2} .
$$

Adding equations B7 and B8 one readily obtains the following relationship for total energy inside an FRC experiment

$$
E_{t o t}=E_{B v}\left[1+(5 / 2) \beta x_{s}^{2} x_{z} /\left(1-x_{s}^{2}\right)^{2}\right] .
$$

Equation B9 is an alternate form of the morefamiliar "Ohi equation,"

$$
E_{t o t}=E_{B v}+5 E_{p} / 3
$$

where $E_{p}$ is the plasma thermal energy. 


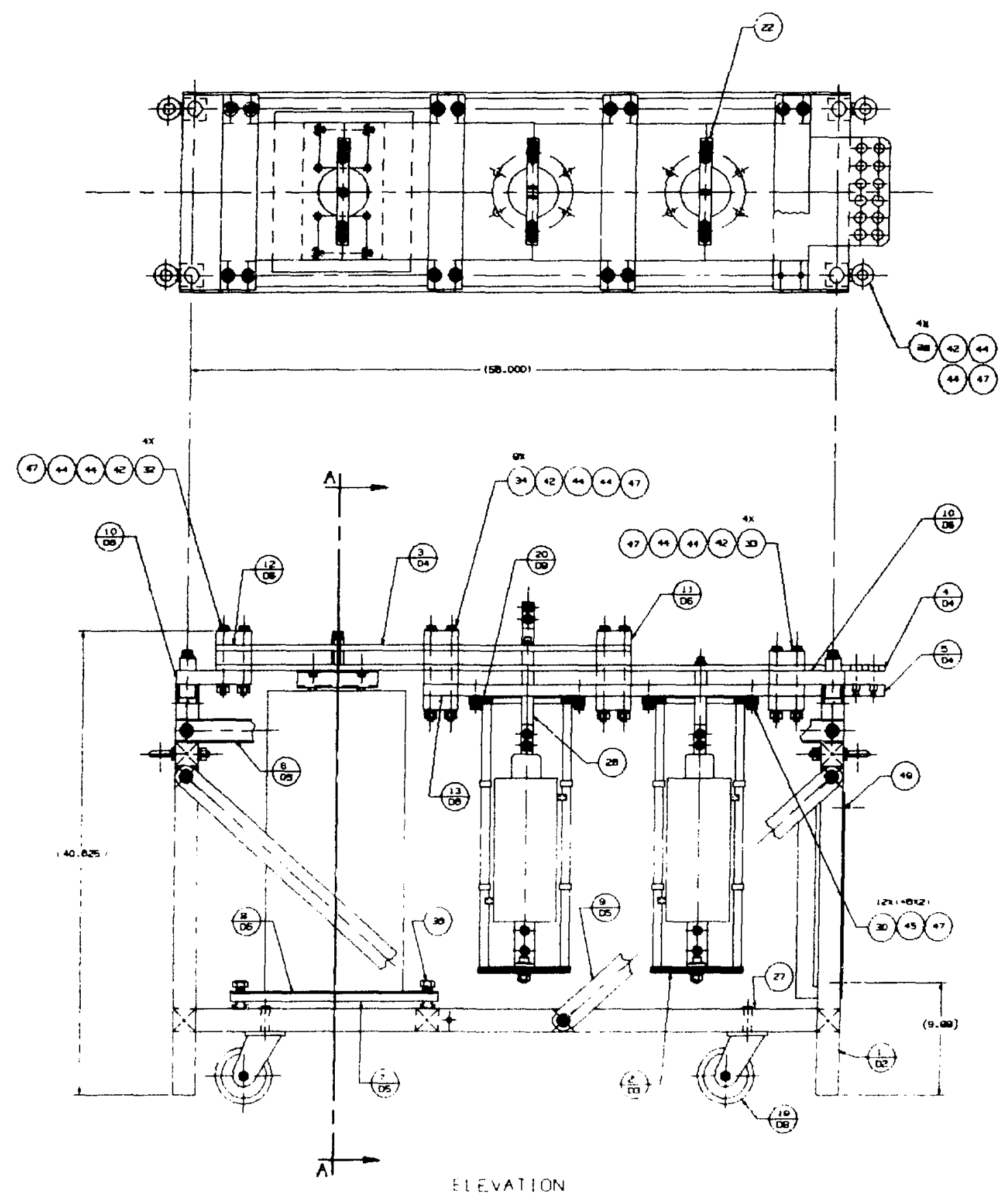




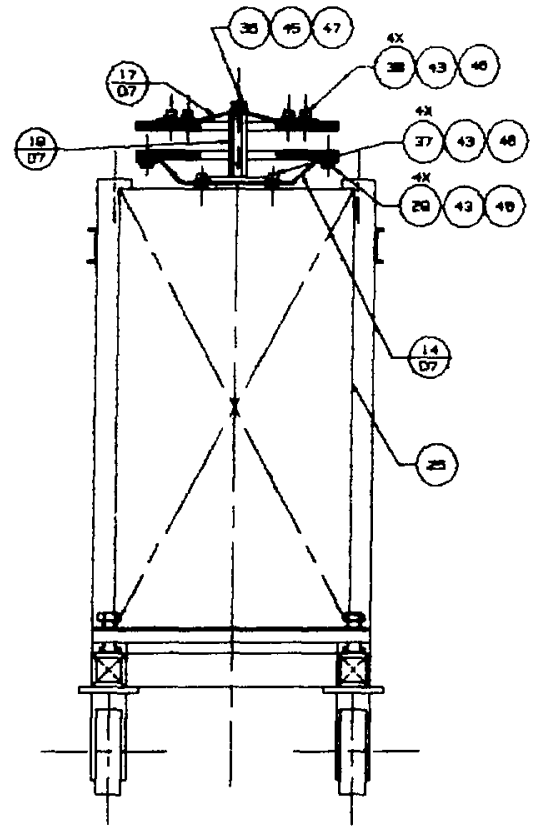

SECTION A-A

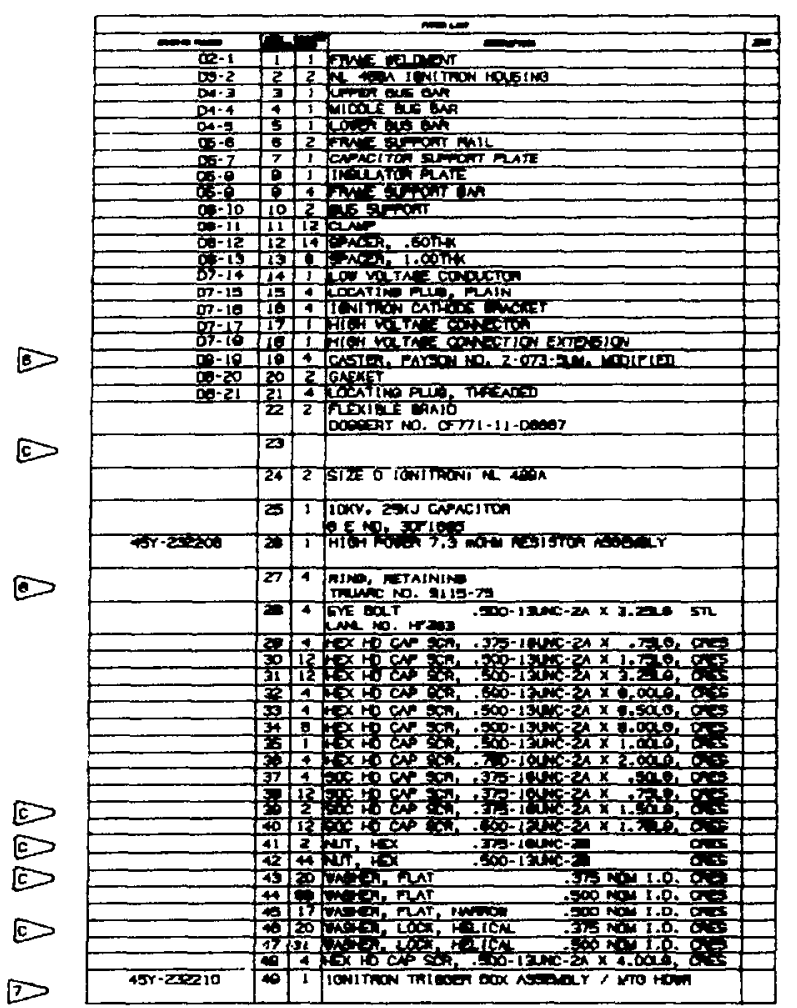

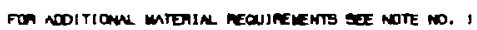
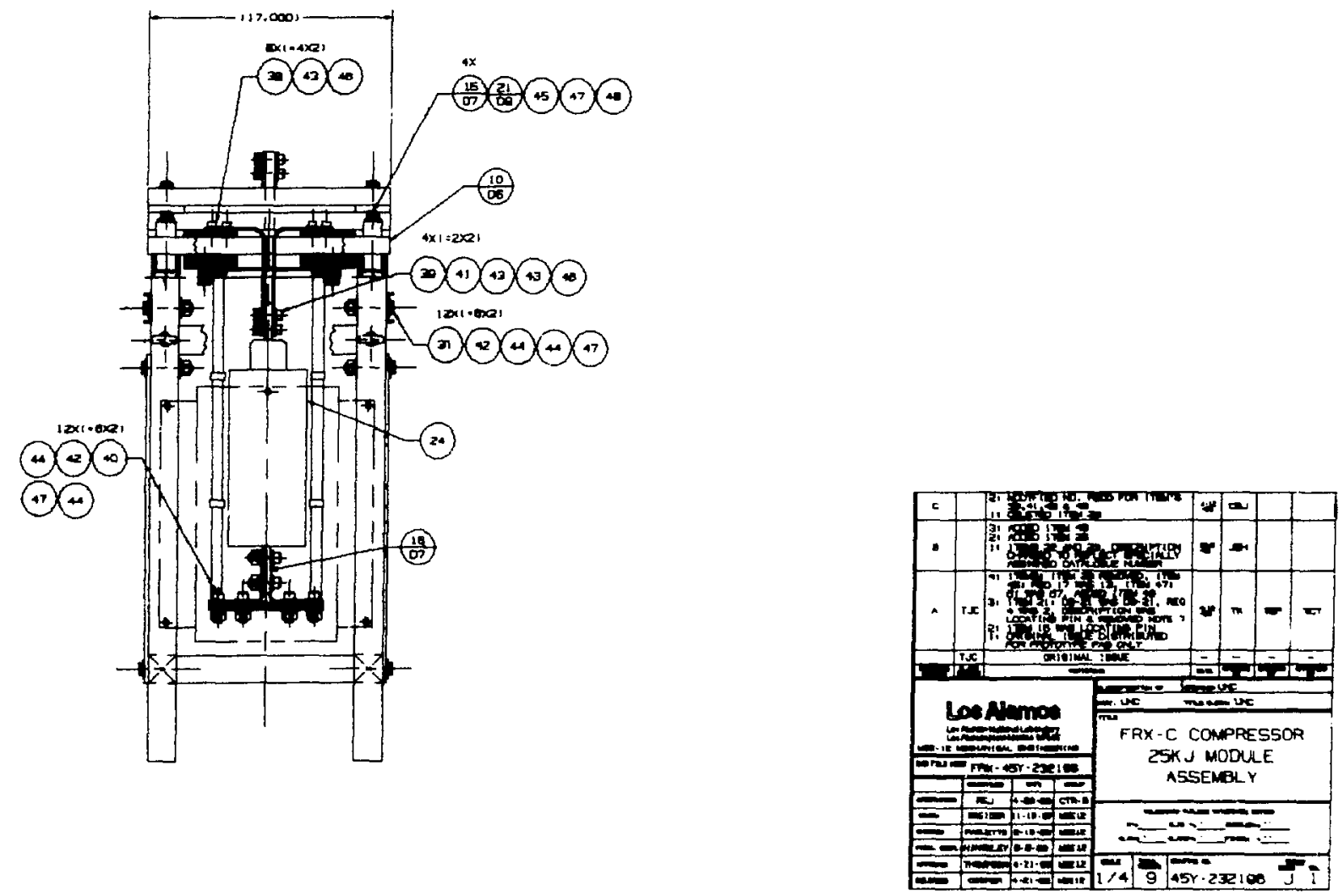


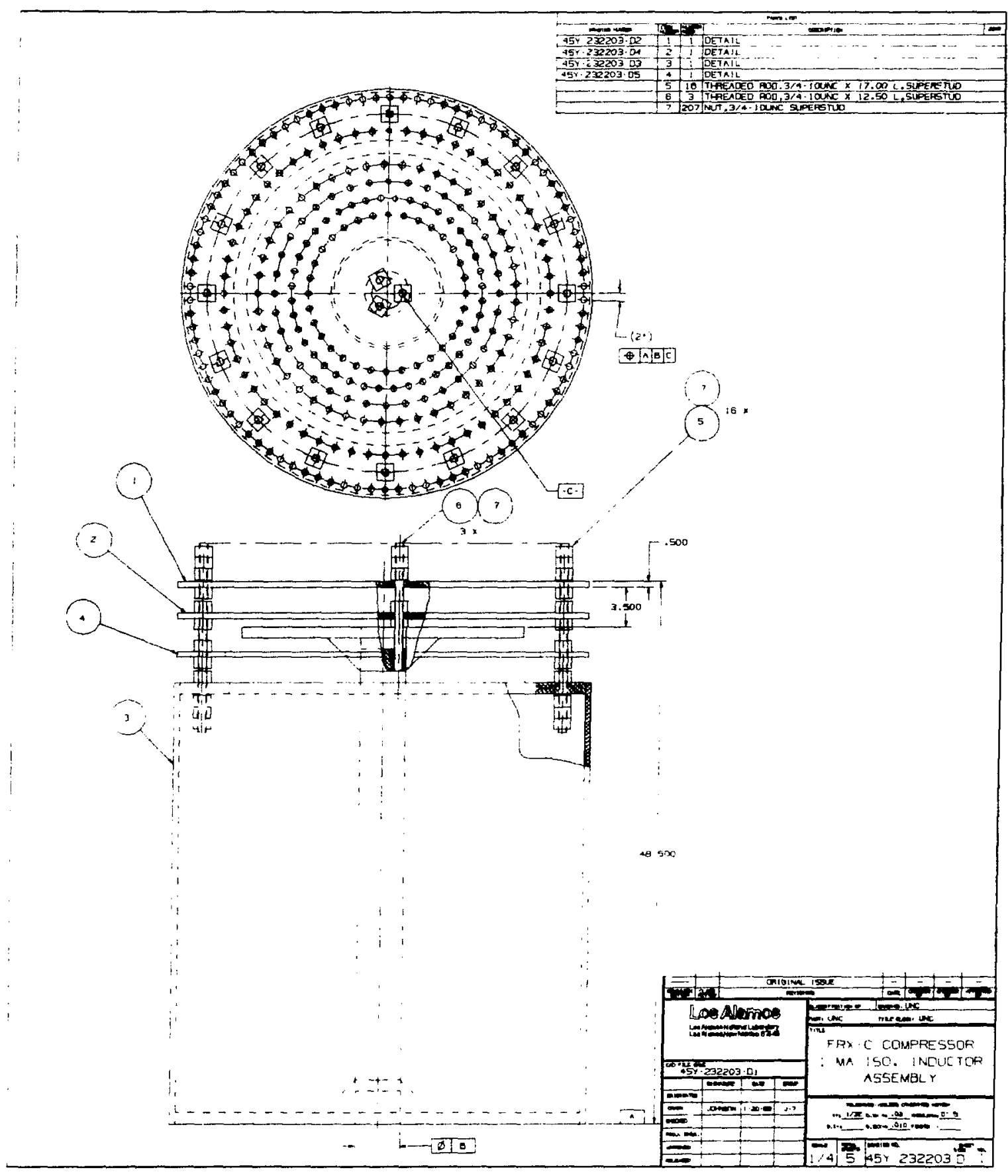

